\title{
Stimulus specificity of concurrent recovery in the rabbit nictitating membrane response
}

\author{
GABRIELLE WEIDEMANN and E. JAMES KEHOE \\ University of New South Wales, Sydney, Australia
}

\begin{abstract}
Three experiments demonstrated that, following the extinction of an established conditioned stimulus (CS; e.g., tone), the pairing of an orthogonal stimulus from another modality (e.g., light) with the unconditioned stimulus (US) results in strong recovery of responding to the extinguished CS. This recovery occurred to about an equal degree regardless of whether or not initial training contained unambiguous stimulus-reinforcer relationships - that is, consistent CS-US pairings-or some degree of ambiguity, including intramodal discrimination training, partial reinforcement, or even cross-modal discrimination training (tone vs. light). Experiments 1 and 2 demonstrated that this recovery of responding was largely specific to the extinguished CS, but moderate generalization to other stimuli from the same modality did appear. The results are discussed with reference to alternative mechanisms applicable to learning-dependent generalization between otherwise distinct CSs. These models assume that such generalization is mediated by either a shared response, shared reinforcer, shared context, or shared hidden units within a layered neural network. A specific layered network is proposed to explain the present results as well as other types of savings seen previously in conditioning of the rabbit nictitating membrane response.
\end{abstract}

Recovery of a conditioned response (CR) after its extinction is both familiar and mysterious. Dating back to Pavlov (1927), CRs have been readily recovered in three different ways. First, there is spontaneous recovery, in which an extinguished CR can reappear when the conditioned stimulus (CS) is presented after a period of rest (Pavlov, 1927, p. 58). Second, there is rapid reacquisition. Even when spontaneous recovery has been eradicated by repeated extinction sessions, the $\mathrm{CR}$ can be reacquired rapidly if pairings of the CS with the unconditioned stimulus (US) are resumed (Pavlov, 1927, p. 60). Third, there is external disinhibition, in which an extinguished CR reappears when the CS is presented in compound with a novel CS (Pavlov, 1927, pp. 62-64). Effects like external disinhibition have also been seen in (1) renewal, which occurs when the extinguished CS is presented in a changed context, and (2) reinstatement, which occurs when the extinguished CS is presented following US-alone presentations (Bouton \& Nelson, 1998).

Recently, studies by Kehoe and his associates using the rabbit nictitating membrane (NM) preparation have demonstrated a new technique for recovering the $\mathrm{CR}$ to an extinguished CS, which has been denoted concurrent recovery. In this procedure, a stimulus from one modality (CSA, e.g., tone) is first paired with the US and is then extinguished. After all responding to CSA has been eliminated, a new stimulus from a different modality (CSB,

Preparation of this manuscript was supported by Australian Research Council Grant DP0344082. Correspondence should be sent to E. James Kehoe, School of Psychology, University of New South Wales, Sydney, NSW 2052, Australia (e-mail: j.kehoe@unsw.edu.au). e.g., light) is introduced and paired with the US. During CSB-US training, CSA is tested occasionally without reinforcement. As responding is acquired to CSB, responding to CSA recovers up to $75 \%$ of its original strength, despite its not having been reinforced since initial acquisition training (Kehoe, Horne, \& Macrae, 1995; Macrae \& Kehoe, 1999; Weidemann \& Kehoe, 2003, 2004).

Concurrent recovery is distinct from other forms of recovery after extinction. With regard to spontaneous recovery, Weidemann and Kehoe (2003) tested CSA immediately prior to the start of CSB-US training. No responding appeared to CSA. With regard to external disinhibition and renewal, demonstrations of concurrent recovery have not involved presentation of CSA in a compound with either another discrete stimulus (external disinhibition) or a new context (renewal). With regard to reinstatement, previous tests of reinstatement in the rabbit NM preparation have repeatedly failed to reveal any significant recovery in responding to an extinguished CS as a result of US-alone presentations (Napier, Macrae, \& Kehoe, 1992; Weidemann \& Kehoe, 2004).

On the face of it, concurrent recovery appears to be a form of cross-modal generalization to the extinguished CSA from CSB as it undergoes pairings with the US. However, previous investigations using the rabbit NM preparation have strongly indicated that cross-modal transfer does not appear under the same conditions as generalization within a sensory modality. In the conventional assay for stimulus generalization, reinforced training is conducted with one CS and then testing is conducted with other stimuli that themselves are relatively novel. For example, the rabbit NM preparation shows a gradient of generalized responding from a tone $\mathrm{CS}$ to test tones with similar 
frequencies (e.g., Garcia, Mauk, Weidemann, \& Kehoe, 2003; Moore, 1972). In contrast, there is no evidence that NM responding shows generalization across modalities, even at a subthreshold level. Kehoe (1992) collated the results of several studies, in which 126 rabbits received initial NM training with a CS in one modality and then received conventional tests for generalization to a new CS in a different modality. Another set of 117 animals, which had not received the initial training, were tested as controls. Both trained and control animals showed negligible levels of responding to the test CS. Given the large sample size, there was more than adequate statistical power to detect even weak generalization.

Recently, two studies with the rabbit NM preparation have examined the potential contribution of cross-modal generalization to concurrent recovery (Macrae \& Kehoe, 1999; Weidemann \& Kehoe, 2004). In both cases, the contribution was at most very small. For example, Weidemann and Kehoe (2004) conducted a within-subjects study of concurrent recovery in which stimuli from three different modalities (tone, light, and skin vibration) were assigned to roles as CSA, CSB, and CSC in a counterbalanced fashion. Initial CSA-US acquisition training was followed by CSA - extinction training and then CSB-US training. During CSB-US training, CSA was tested for concurrent recovery, and CSC was tested for cross-modal generalization. There was strong recovery in responding to the trained and extinguished CSA ( $>45 \%$ CRs) and virtually no generalized responding to the novel stimulus, $\mathrm{CSC}(<5 \% \mathrm{CRs})$.

Although there is virtually no evidence for conventional generalization across modalities in the rabbit NM preparation, there is strong evidence that cross-modal generalization does emerge when the test stimulus has received even brief pretraining. Schreurs and Kehoe (1987) gave two groups of rabbits reinforced pretraining with either 15 or 30 CSA-US pairings. These few CSA-US pairings yielded negligible responding to CSA. Subsequently, the animals received 240 reinforced trials using a stimulus from another modality (CSB-US). During CSB-US training, the animals were tested with CSA. As CRs were acquired to CSB, both pretrained groups showed progressive increases in responding on CSA test trials to levels of $34 \%$ and $62 \%$ CRs, respectively. In contrast, a control group that had not received CSA-US pretraining showed no generalized responding to CSA $(M=0 \% \mathrm{CRs})$ during CSB-US training.

The learning-dependent cross-modal generalization seen by Schreurs and Kehoe (1987) may also underpin concurrent recovery. In other words, as a result of CSA's initial reinforced training, the extinguished responding to CSA may become subject to cross-modal generalization during CSB-US training. One question that arises concerns whether learning-dependent generalization from CSB is specific to CSA or if the training of the two CSs from orthogonal modalities may induce widespread generalization to any test CS in either of the modalities. On the one hand, cross-modal generalization could be mediated by specific associative linkages. These could in- clude shared linkages from CSA and CSB to the response (Miller \& Dollard, 1941, pp. 62-65), to the reinforcer (Honey \& Hall, 1989; Overmier \& Lawry, 1979; Peterson \& Trapold, 1980), and/or to the context (Blaisdell, Bristol, Gunther, \& Miller, 1998), all of which might yield something like the acquired equivalence of cues seen in operant conditioning (e.g., Delamater, 1998; Hall, 1996; Johns \& Williams, 1998). On the other hand, reinforced training with CSs from different modalities may have a relatively nonspecific effect on stimulus encoding that broadens generalization between, and perhaps even within, modalities. In neuroanatomical terms, training with orthogonal CSs may sensitize activity in polysensory areas (Gabriel, Wheeler, \& Thompson, 1973).

The primary aim of the present experiments was to determine the specificity of concurrent recovery to CSA. A secondary aim was to determine whether concurrent recovery is affected by initial discriminative training between CSA and a physically related stimulus, namely, discrimination between two tones of different frequencies $(500$ vs. $5000 \mathrm{~Hz})$. A variety of outcomes is theoretically plausible. First, if concurrent recovery is mediated by relatively specific associative linkages, the recovery of responding to CSA and the discrimination between the two tones would be left intact. Second, initial discrimination training could increase the specificity of concurrent recovery to CSA and conversely reduce any nonspecific increase in cross-modal generalization. Third, discrimination training introduces a degree of overall ambiguity into a set of stimulus-reinforcer relationships - one tone being reinforced and the other tone being nonreinforced - that could reduce concurrent recovery to CSA itself during CSB-US training. Up until now, studies of concurrent recovery have always used consistent stimulus-reinforcer relationships within each training phase.

\section{EXPERIMENT 1}

Experiment 1 contained three groups. Specifically, Group Single was initially given reinforced acquisition training with a single-tone stimulus $(\mathrm{T} 1+)$, which then underwent extinction training $(\mathrm{T} 1-)$. Then, this group received cross-modal acquisition training using a light stimulus $(\mathrm{L}+)$. During $\mathrm{L}+$ training, responding was assessed with two test stimuli. One was the previously trained and extinguished tone (T1), and the other was a novel tone (T2). If concurrent recovery is specific to the trained and extinguished tone, then only $\mathrm{T} 1$ should elicit appreciable responding. However, if concurrent recovery reflects nonspecific cross-modal generalization from the $\mathrm{L}+$ training to all auditory stimuli, then both $\mathrm{T} 1$ and $\mathrm{T} 2$ should elicit considerable responding.

Group Discrim was initially trained in a two-tone discrimination, in which one tone was consistently paired with the US (T1+) and a second tone was presented without reinforcement (T2-). During subsequent extinction training of $\mathrm{T} 1$, nonreinforced presentations of $\mathrm{T} 2$ were continued. Thus, the animals received equal exposure to both tones. During final cross-modal acquisition training 
$(\mathrm{L}+)$, responding to both tones was tested to determine whether the recovery of responding to $\mathrm{T} 1 \mathrm{and} /$ or generalization to $\mathrm{T} 2$ were affected by their initial discrimination training.

Finally, Group Pseudo was included to introduce ambiguity into the stimulus-reinforcer relationships but without discrimination training. Group Pseudo was also equated to Group Discrim for exposure to the two CSs. That is, Group Pseudo initially received training in which both tones were reinforced under a $50 \%$ partial reinforcement schedule (T1 \pm , T2 \pm ). During extinction training, both tones were presented without reinforcement (T1-, T2-) as in Group Discrim. Subsequently, responding to both tones was tested during cross-modal acquisition training $(\mathrm{L}+)$.

\section{Method}

Subjects. The subjects were 24 female, albino rabbits (Oryctolagus cuniculus). On arrival from the commercial breeding unit, they were $70-80$ days old and weighed approximately $1.5 \mathrm{~kg}$. All rabbits were individually housed and had free access to food and water.

Apparatus. During training, each subject was restrained in a Perspex box (internal dimensions: $43 \times 12 \times 17 \mathrm{~cm}$ ). Each rabbit was held in place by insertion of its head through an adjustable stock and by securing its ears to the front of the stock with a polyurethane foam-covered metal clamp. The rabbits were trained individually in one of eight sound-attenuating chambers. In each chamber, a speaker was mounted approximately $8 \mathrm{~cm}$ anterior to and $16 \mathrm{~cm}$ above the subject's head. The speaker delivered the auditory CSs, which were a $500-\mathrm{Hz}, 88-\mathrm{dB}$ (SPL) tone and a $5000-\mathrm{Hz}, 88-\mathrm{dB}$ (SPL) tone, both of $250-\mathrm{msec}$ duration. A constant background noise ( $81 \mathrm{~dB}, \mathrm{SPL})$ was provided by a ventilating fan positioned at the rear of the conditioning chamber. Mounted on the stimulus panel, $4 \mathrm{~cm}$ above the speaker, was an $8-\mathrm{W}$ neon light that served as the houselight. A visual CS was provided by a $20-\mathrm{Hz}$ flashing of the houselight for $250 \mathrm{msec}$. The US was a $50-\mathrm{msec}, 3-\mathrm{mA}, 50-\mathrm{Hz}$ AC electric current delivered via 9-mm stainless steel Autoclip wound clips positioned $10 \mathrm{~mm}$ apart and $15 \mathrm{~mm}$ posterior to the dorsal canthus of the rabbit's right eye. The sequence and timing of stimulus events were controlled by an Apple II computer equipped with interfaces and software developed by Scandrett and Gormezano (1980).

The apparatus and recording procedures for the NM response were modeled on those described by Gormezano (1966). Each rabbit wore a muzzle-like headset that fitted securely about the snout and supported a photoelectric transducer for detecting movements of the NM. A small, tinned copper wire hook was attached to a silk loop sutured into the NM of the rabbit's right eye. The other end of the hook was connected by a ball joint to a L-shaped crank, which operated the photoelectric transducer (Gormezano \& Gibbs, 1988). The signal from the phototransistor was amplified and transmitted to an analog-digital converter (10-msec sample rate) installed in the computer.

Procedure. Each rabbit received 1 day of preparation, 2 days of recovery, 1 day of adaptation, and 15 days of training and testing. On preparation day, hair surrounding each rabbit's right eye was removed and a small loop of surgical silk (000 Dynex) was sutured into the NM of the rabbit's right eye using a local anaesthetic (proxymetacaine hydrochloride). The rabbits were returned to their home cages for 2 days of recovery following preparation. On the adaptation day, the rabbits were placed in the conditioning apparatus for $60 \mathrm{~min}$, but no stimuli were presented.

On the day following adaptation, the rabbits were randomly assigned to one of three groups $(n=8)$ designated Single, Discrim, and Pseudo according to the type of training they received in Stage 1.
In brief, Group Single received acquisition training with a single tone, Group Discrim received discrimination training with two different tones, and Group Pseudo received pseudodiscrimination training with two different tones.

In Stage 1, which lasted for 5 days, Group Single received 30 pairings of a tone CS with the US (T1+) per day. For half of the animals in Group Single, this was the $500-\mathrm{Hz}$ tone, and for the other half of the animals, this was the $5000-\mathrm{Hz}$ tone. Group Discrim received 30 pairings of a tone CS with the US $(\mathrm{T} 1+)$ and 30 presentations of a different tone CS in the absence of reinforcement (T2-) per day. For half of the animals in Group Discrim, the $500-\mathrm{Hz}$ tone was reinforced and the $5000-\mathrm{Hz}$ tone was presented without reinforcement. For the other half of the animals in Group Discrim, the $5000-\mathrm{Hz}$ tone was reinforced and the $500-\mathrm{Hz}$ tone was presented without reinforcement. Group Pseudo received 30 presentations of each of the two-tone CSs, which were paired with the US on half of the presentations and were presented in the absence of reinforcement on the other half of the presentations (T1,$\pm \mathrm{T} 2 \pm$ ) per day. The CS-US interval (onset to onset) was 250-msec for all paired trials.

For all three groups, each session contained 60 trials separated by a mean intertrial interval (ITI) of $60 \mathrm{sec}$, measured from the start of one trial to the start of the next (range, 50-70 sec). For Group Single, each block of 20 trials contained 10 reinforced trials and 10 "blank" trials containing no programmed stimuli. For Group Discrim, each block of 20 trials had 10 reinforced trials of T1 and 10 nonreinforced trials of T2. Finally, for Group Pseudo, each block of 20 trials had 5 reinforced trials and 5 nonreinforced trials of each of the tone CSs. Thus, the total duration of the session was equated for all groups.

For Group Single, the mean ITI between trials containing a CS was effectively twice as long as that of the other two groups $(M=$ $120 \mathrm{sec}$ ). A comprehensive review of the rabbit NM literature has indicated that ITIs in the range of 30-300 sec yield similar rates of CR acquisition, especially when they are variable, as they were in the present experiments (Kehoe \& Macrae, 2002, pp. 194-195; Mitchell, 1974).

In Stage 2, which lasted for 6 days, all three groups received extinction training. Group Single received, per day, 30 nonreinforced presentations of the single tone CS ( $\mathrm{T} 1-)$ that had been previously reinforced in Stage 1. Groups Discrim and Pseudo each received 30 nonreinforced presentations of the two-tone CSs (T1-, T2-), which were presented in Stage 1, per day. Each block of 10 trials had five trials with each of the tone CSs. The pattern of ITIs was the same as it had been for each group in Stage 1.

In Stage 3, which lasted for 4 days, all three groups received training with the light CS paired with the US ( $\mathrm{L}+$ ). On each day, all three groups received $60 \mathrm{~L}+$ trials plus six test trials of each of the tone CSs. Each block of 12 trials had $10 \mathrm{~L}+$ trials that were interspersed with a test trial for $\mathrm{T} 1$ and a test trial for $\mathrm{T} 2$. For all groups, the mean ITI was $60 \mathrm{sec}$ (range, 50-70 sec). The design of this experiment plus the designs of the subsequent experiments reported in this article are summarized in Table 1.

Table 1 Experimental Designs

\begin{tabular}{|c|c|c|c|c|}
\hline Group Label & Stage 1 & Stage 2 & Stage 3 & Test Stimuli \\
\hline \multicolumn{5}{|l|}{ Experiment 1} \\
\hline Single & $\mathrm{T} 1+$ & $\mathrm{T} 1-$ & $\mathrm{L}+$ & $\mathrm{T} 1-/ \mathrm{T} 2-$ \\
\hline Discrim & $\mathrm{T} 1+/ \mathrm{T} 2-$ & $\mathrm{T} 1-/ \mathrm{T} 2-$ & $\mathrm{L}+$ & $\mathrm{T} 1-/ \mathrm{T} 2-$ \\
\hline Pseudo & $\mathrm{T} 1 \pm / \mathrm{T} 2 \pm$ & $\mathrm{T} 1-/ \mathrm{T} 2-$ & $\mathrm{L}+$ & $\mathrm{T} 1-/ \mathrm{T} 2-$ \\
\hline \multicolumn{5}{|l|}{ Experiment 2} \\
\hline DE & $\mathrm{T} 1+/ \mathrm{T} 2-$ & $\mathrm{T} 1-/ \mathrm{T} 2-$ & $\mathrm{L}+$ & $\mathrm{T} 1-/ \mathrm{T} 2-$ \\
\hline $\mathrm{DR}$ & $\mathrm{T} 1+/ \mathrm{T} 2-$ & $\mathrm{T} 1-/ \mathrm{T} 2+$ & $\mathrm{L}+$ & $\mathrm{T} 1-/ \mathrm{T} 2-$ \\
\hline \multicolumn{5}{|c|}{ Experiments $3 \mathrm{~A}$ and $3 \mathrm{~B}$} \\
\hline CMD & $\mathrm{CSA}+/ \mathrm{CSB}-$ & CSA- & $\mathrm{CSB}+$ & $\mathrm{CSA}-$ \\
\hline SST & $\mathrm{CSA}+$ & CSA- & $\mathrm{CSB}+$ & $\mathrm{CSA}-$ \\
\hline
\end{tabular}


Response definition. A CR was defined as any extension of the $\mathrm{NM}$ greater than or equal to $0.5 \mathrm{~mm}$ that occurred following the onset of the CS but prior to its termination (Marshall-Goodell, Schreurs, \& Gormezano, 1982)

\section{Results}

Unless otherwise noted, planned contrasts were used to analyze the data, and the rejection level was set according to a Type I error rate of .05 (Harris, 1994; O'Brien \& Kaiser, 1985). Because Experiment 1 focused on recovery of responding in Stage 3, rigorous criteria were applied to ensure that each subject had shown both sufficient acquisition by the end of Stage $1(>50 \%$ CRs) and complete extinction of responding by the end of Stage $2(<10 \%$ $\mathrm{CRs}$ ). One animal in Group Single failed to meet the criteria for extinction; it persisted in responding at levels of more than $75 \%$ CRs throughout all 6 days of extinction. Accordingly, its data were excluded from the analysis and presentation of the data. In addition, 1 animal in Group Discrim and 1 animal in Group Single developed an eye infection in Stage 3, and NM responding could not be re- corded for these animals. Thus, Group Discrim and Group Single were reduced to 7 and 6 animals, respectively. Figure 1 depicts mean percent $\mathrm{CR}$ performance during the three stages of Experiment 1, based on the reduced sample sizes.

Stage 1: Initial acquisition. The left-hand panels of Figure 1 show the mean percentage CRs for each group plotted across the 5 days of Stage 1. Each day is divided into six blocks of 10 trials. There is a separate panel for each group. For Group Single, the acquisition curve for responding to T1 + is shown; for Group Discrim, the acquisition curve of discriminative responding to T1 + versus T2is shown; and for Group Pseudo, the acquisition curve of responding to both partially reinforced tones is shown.

The curves show that all three groups acquired CRs to the reinforced tones to asymptotic levels exceeding $85 \%$ CRs ( $\pm 8 \%$ SEM). The acquisition curves of the reinforced tones in the three groups appeared to be very similar despite differences in reinforcement schedules; any apparent differences between them failed to attain statistical significance [largest $F(1,20)=1.76, p>.10$ ]. As
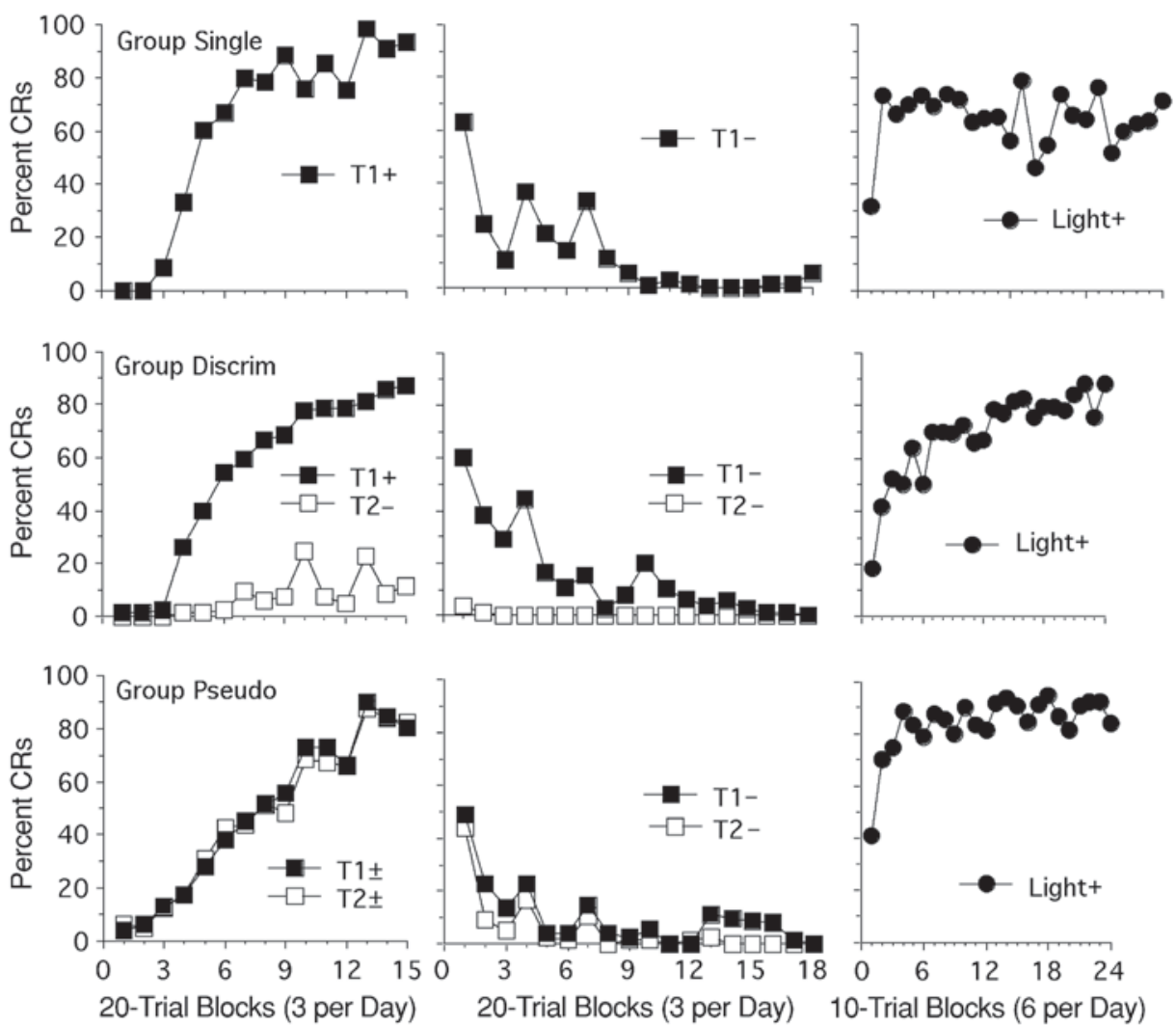

Figure 1. Percentage of CRs in the three successive stages of Experiment 1. Each row of panels shows the results of a different group. In Stage 1 (left panels), Group Single received continuous reinforcement of a single tone $(\mathrm{T} 1+)$, Group Discrim received differential conditioning of two tones $(\mathrm{T} 1+, \mathrm{T} 2-)$, and Group Pseudo received partial reinforcement of two tones (T1, $\pm T 2 \pm)$. In Stage 2 (middle panels), Group Single received nonreinforced presentations of the previously reinforced tone (T1-), Group Discrim received nonreinforced presentations of the previously reinforced tone (T1-) as well as of the previously nonreinforced tone (T2-), and Group Pseudo received nonreinforced presentations of the two partially reinforced tones (T1-, T2-). In Stage 3 (right panels), all three groups received reinforced presentations of a light CS (+). 
can be seen in Figure 1, Group Discrim acquired discriminative responding to the two different tones in Stage 1 $[F(1,20)=41.47, p<.05]$, whereas Group Pseudo did not respond differentially to the two tones $(F<1)$.

Stage 2: Extinction. The middle panels of Figure 1 show the mean percentage of CRs during extinction of responding to the previously reinforced tone stimuli in all three groups. As can be seen from the figure, extinction was complete by the second-to-last day of Stage 2. On that day, the highest level of responding in any trial block was only $11 \%$ CRs ( $\pm 9 \% S E M)$. The extinction curves of the three groups were similar; any apparent differences between them failed to attain statistical significance [largest $F(1,20)=2.47, p>.10]$.

Stage 3: Cross-modal acquisition. The right-hand panels of Figure 1 show the mean percentage of CRs during acquisition to the light CS in all three groups in Stage 3. Acquisition on $\mathrm{L}+$ trials was rapid, with all three groups showing substantial levels of responding within the first 10 -trial block $(M=30 \% \mathrm{CRs}, \pm 6 \% S E M)$. However, the mean level of responding on the first day was somewhat lower in Group Discrim $(M=46 \% \mathrm{CRs}, \pm 12 \% S E M)$ than in either Group Pseudo $(M=73 \% \mathrm{CRs}, \pm 8 \%$ SEM $)$ or Group Single $(M=64 \% \mathrm{CRs}, \pm 13 \% S E M)$. This apparent difference, however, was not statistically significant either in overall comparisons or in interactions with trial blocks [largest $F(1,18)=3.33, p>.05]$. As training progressed, all three groups showed stable levels of responding. The mean level of responding on the last day was somewhat, although not significantly, lower in Group Single $(M=65 \% \mathrm{CRs}, \pm 12 \% S E M)$ than in either Group Discrim $(M=82 \% \mathrm{CRs}, \pm 10 \% S E M)$ or Group Pseudo $(M=88 \% \mathrm{CRs}, \pm 7 \% \operatorname{SEM})[F(1,18)=3.27, p>.05]$.

Stage 3: Concurrent recovery. Figure 2 shows the mean percentage CRs on test trials with the two tones as a function of days in Stage 3. The error bars around each mean represent one standard error. Whereas responding to the tones was entirely absent at the end of Stage 2 extinction training, Figure 2 shows that all three groups showed considerable recovery of responding to the tones that had been paired with the US in Stage 1. In Group Single, the mean level of responding to the tone that had been previously reinforced (T1) was $65 \% \mathrm{CRs}( \pm 12 \% S E M)$, but the overall mean level of responding to the novel tone (T2) was $14 \%$ CRs $( \pm 7 \%$ SEM), most of which appeared on the first day of Stage $3(M=36 \% \mathrm{CRs}, \pm 15 \%$ SEM $)$. In Group Discrim, the mean level of responding to T1 was $59 \%$ CRs ( $\pm 14 \% S E M)$, a level similar to that elicited by T1 in Group Single. Group Discrim showed a modest but appreciable level of responding to T2 $(M=25 \% \mathrm{CRs}$, $\pm 11 \%$ SEM), which had been presented in the absence of reinforcement during both Stages 1 and 2. In Group Pseudo, the mean level of responding to both tones, both of which had been previously trained under conditions of partial reinforcement, was $52 \%$ CRs $( \pm 12 \%$ SEM), which approached the levels of recovery to T1 shown by Groups Single and Discrim.

Statistical comparisons confirmed the main effect of stimulus (T1 vs. T2) $[F(1,18)=39.61, p<.01]$. More importantly, there were significant interactions between group (Discrim vs. Pseudo; Single vs. Pseudo) and stimulus $(\mathrm{T} 1$ vs. T2) $[F \mathrm{~s}(1,18)=12.57,25.08, p<.05]$, confirming that both Group Single and Group Discrim showed significantly more responding to T1 than T2. Any apparent differences between Groups Discrim and Single were not significant [largest $F(1,18)=2.44, p>.10$ ]. In a post hoc comparison, any apparent differences among the three groups in responding to T1 were not statistically significant $\left(F_{\mathrm{s}}<1\right)$. Although Group Discrim appeared to show greater overall responding to T2 than Group Single, this difference approached but failed to reach the declared level of significance $[F(1,18)=3.25, p>.05]$.

\section{Discussion}

Experiment 1 resulted in the key finding that, when the light CS is paired with the US, there is recovery of extinguished responding to the tone CSs that had been previously paired with the US in either a $100 \%$ rein-
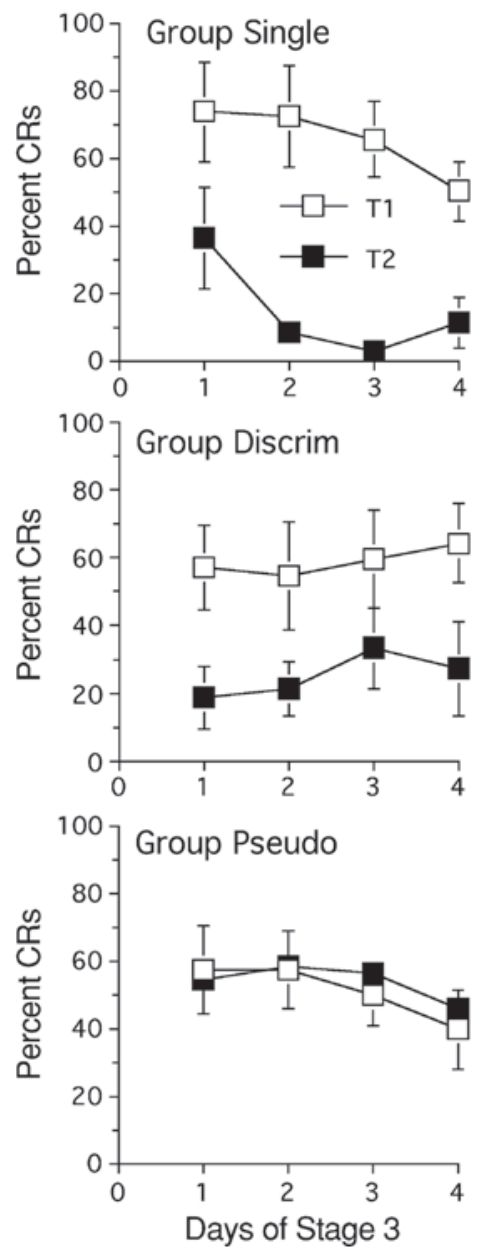

Figure 2. Percentage of CRs on tests of the two tone CSs (T1, T2) as a function of days in Stage 3 of Experiment 1. The tone test trials were distributed among reinforced presentations of the light CS. The top panel shows the results of Group Single, the middle panel shows the results of Group Discrim, and the bottom panel shows the results of Group Pseudo. 
forcement schedule (Group Single), a discrimination schedule (Group Discrim), or a 50\% partial reinforcement schedule (Group Pseudo). These results expand the scope of concurrent recovery. In previous demonstrations, recovery was observed in groups similar to Group Single, in which initial reinforced training and extinction were conducted with the ultimate test stimulus in the absence of any other stimuli. In the present case, equally strong concurrent recovery was seen in animals for which initial reinforced training was conducted in either a discriminative setting or in a partially reinforced fashion with two target stimuli. Hence, concurrent recovery is robust in the face of training paradigms that contain some ambiguity in their stimulus-reinforcer contingencies.

With respect to the specificity of concurrent recovery to $\mathrm{T} 1$, the present results indicate that there was considerable but not complete specificity. That is, there was discernible responding to T2 in both Groups Single and Discrim. Moreover, the degree of specificity was about the same in both groups. In Group Single, the overall level of responding to T1 was $65 \%$ CRs versus $14 \%$ CRs to T2, which was a novel stimulus for that group. Responding to $\mathrm{T} 1$ and $\mathrm{T} 2$ were at their maximum on the first day of Stage 3, in which there were $73 \%$ CRs to T1 and 36\% CRs to T2. These initial levels of responding in Group Single were approximated in Group Discrim's overall pattern of responding. Specifically, Group Discrim showed overall means of $59 \%$ CRs to T1 and $25 \%$ CRs to T2, which had received considerable previous nonreinforced exposure.

Although the degree of specificity was similar in both Groups Single and Discrim, there remains a question as to whether or not the responding to T2 in Stage 3 is diagnostic of a contribution to concurrent recovery from an increase in nonspecific cross-modal generalization. Responding to T2 could reflect an combination of intramodal generalization from T1 plus cross-modal generalization from the light CS. The level of cross-modal generalization can be estimated indirectly from the level of intramodal generalization between $\mathrm{T} 1$ and $\mathrm{T} 2$. In turn, intramodal generalization can be estimated from internal and external evidence. Internally, the discrimination between T1 and T2 in Stage 1 in Group Discrim suggested that there was little or no generalization between the 500$\mathrm{Hz}$ and $5000-\mathrm{Hz}$ tones. Specifically, in Stage 1, Group Discrim showed little or no responding to $\mathrm{T} 2$, whereas responding to T1 steadily rose. However, the explicit discrimination training may have dampened generalized responding to T2. External findings suggest that there may have been sufficient intramodal generalization to explain most of the responding to T2 in Stage 3. Generalization between $500 \mathrm{~Hz}$ versus $5000 \mathrm{~Hz}$ has never been directly assessed in the rabbit NM preparation, but there has been a recent examination of auditory generalization in the rabbit in which a $1000-\mathrm{Hz}$ tone was used as the CS, and testing was conducted using tone frequencies ranging up to $5040 \mathrm{~Hz}$ (Garcia et al., 2003). Responding to the $1000-\mathrm{Hz}$ $\mathrm{CS}$ reached $91 \% \mathrm{CRs}$, and responding to the $5040-\mathrm{Hz}$ test stimulus was $34 \%$ CRs. Even if there was less generaliza- tion to a $5000-\mathrm{Hz}$ tone from the $500-\mathrm{Hz}$ tone than from a $1000-\mathrm{Hz}$ tone, there is good reason to suspect that a substantial portion of responding to T2 resulted from ordinary intramodal generalization and not from nonspecific cross-modal generalization. Hence, concurrent recovery appears to have resulted from shared associative linkages involving T1 and the light CS rather than a more widespread change in polysensory encoding.

\section{EXPERIMENT 2}

Experiment 2 was designed to further determine whether concurrent recovery is specific to a CS that has previously been paired with the US. In particular, this experiment repeated Group Discrim from Experiment 1 but with a change in the testing procedure. In Experiment 1, the test trials for the two tones $(\mathrm{T} 1, \mathrm{~T} 2)$ were interspersed among the $\mathrm{L}+$ trials. In contrast, the test trials in Experiment 2 were presented at the start of each session in Stage 3, prior to the $\mathrm{L}+$ trials. This change was made for two reasons. First, the test trials at the beginning of the very first session of $\mathrm{L}+$ training provided an estimate of any residual spontaneous recovery of extinguished responding to $\mathrm{T} 1$. Second, the test trials at the start of the remaining sessions of $\mathrm{L}+$ training allowed us to confirm that the recovery of responding is independent of any immediate aftereffects of training with the $\mathrm{L}+$ trials and is retained from a previous session (Weidemann \& Kehoe, 2004).

Experiment 2 was also designed to examine whether the treatment of the CS following initial acquisition training affected the amount of subsequent concurrent recovery. In particular, Experiment 2 examined whether the amount of concurrent recovery as a result of conventional extinction is different from the amount of concurrent recovery as a result of extinction during a discrimination reversal.

Experiment 2 contained two groups. Both groups initially received discrimination training with the two-tone CSs used in Experiment $1(\mathrm{~T} 1+, \mathrm{T} 2-)$. In Stage 2, Group $\mathrm{DE}$ received extinction training during which both tones were presented without reinforcement $(\mathrm{T} 1-, \mathrm{T} 2-)$, just as Group Discrim did in Experiment 1. The second group, Group DR, received discrimination reversal training in which the previously reinforced tone underwent extinction training $(\mathrm{T} 1-)$, whereas the previously nonreinforced tone was presented with reinforcement (T2+). In Stage 3, both groups were tested for responding to the two tones $(\mathrm{T} 1, \mathrm{~T} 2)$ during cross-modal training with a novel light CS (L+).

\section{Method}

Subjects. The subjects were 16 female, albino rabbits.

Apparatus and Procedure. Unless otherwise mentioned, the apparatus and procedure were identical to those of Experiment 1. On the third day following adaptation, rabbits were randomly assigned to one of two groups designated Group DE and Group DR, according to the conditioning treatment that they received in Stage 2.

Stage 1 training lasted for 5 days, and both groups received training in a two-tone discrimination. On each day, all animals received 30 pairings of a tone CS with the US $(\mathrm{T} 1+)$ and 30 presentations 
of a different tone CS in the absence of reinforcement (T2-). Each block of 20 trials had 10 reinforced trials and 10 nonreinforced trials. For half of the animals in each group, the $500-\mathrm{Hz}$ tone was reinforced and the $5000-\mathrm{Hz}$ tone was presented without reinforcement. For the other half of the animals, this stimulus assignment was reversed. The ITI was $60 \mathrm{sec}$ (range, $50-70 \mathrm{sec}$ ).

Stage 2 training lasted for 8 days. Group DE received 30 nonreinforced presentations of the two-tone CSs $(\mathrm{T} 1-, \mathrm{T} 2-)$ per day. Each block of 20 trials had 10 nonreinforced presentations of each of the tone CSs. Group DR received 30 pairings of the previously unreinforced tone with the US (T2+) and 30 presentations of the previously reinforced tone in the absence of reinforcement $(\mathrm{T} 1-)$ per day. Each block of 20 trials had $10 \mathrm{~T} 2+$ trials and $10 \mathrm{~T} 1-$ trials

In Stage 3, which lasted for 4 days, both groups received 60 training trials of the light CS paired with the US $(\mathrm{L}+)$. On each day, both groups also received two test trials of T1 and two test trials of T2. These trials were presented in random order at the very beginning of each session, prior to any $\mathrm{L}+$ trials.

\section{Results}

Stage 1: Acquisition. The left-hand panels of Figure 3 show the acquisition of discriminative responding for both groups plotted across the 5 days of Stage 1. There is a separate panel for each group. Each day is divided into three blocks of $10 \mathrm{~T} 1+$ trials and three blocks of $10 \mathrm{~T} 2-$ trials. Inspection of Figure 3 reveals that both groups acquired discriminative responding to the two tones $[F(1,14)=$ 95.72, $p<.05]$. Any apparent differences between the two groups failed to attain statistical significance [largest $F(1,14)=2.15, p>.10]$.

Stage 2: Extinction and reversal. The middle panels of Figure 3 show the extinction of discriminative responding in Group DE and the acquisition of the reversed discrimination in Group DR. From the figure, it can be seen that in Group DE, extinction of responding to the previously reinforced CS (T1) was complete by the 6th day of Stage 2. In contrast, responding to T1 in Group DR persisted throughout Stage 2. Statistical analysis confirmed that Group DR showed a higher level of responding on $\mathrm{T} 1-$ trials than did Group DE $[F(1,14)=$ $5.13, p<.05]$. In particular, between-session recovery was more pronounced in Group DR than in Group DE. This was confirmed by a significant interaction between groups and the difference in responding on the last block of one session versus the first block of the next session $[F(1,14)=8.02, p<.05]$.

Although some responding to the previously reinforced CS (T1) persisted in Group DR, discriminative responding, consistent with the reversed reinforcement schedule, was clearly established by the 7th day of Stage 2 (Trial Blocks 19-21). A follow-up test confirmed that, on the final day of Stage 2, responding to T2 $(M=71 \% \mathrm{CRs}$, $\pm 9 \% S E M)$ was significantly greater than responding to T1 $(M=15 \% \mathrm{CRs}, \pm 7 \% \operatorname{SEM})[F(1,7)=89.90, p<$
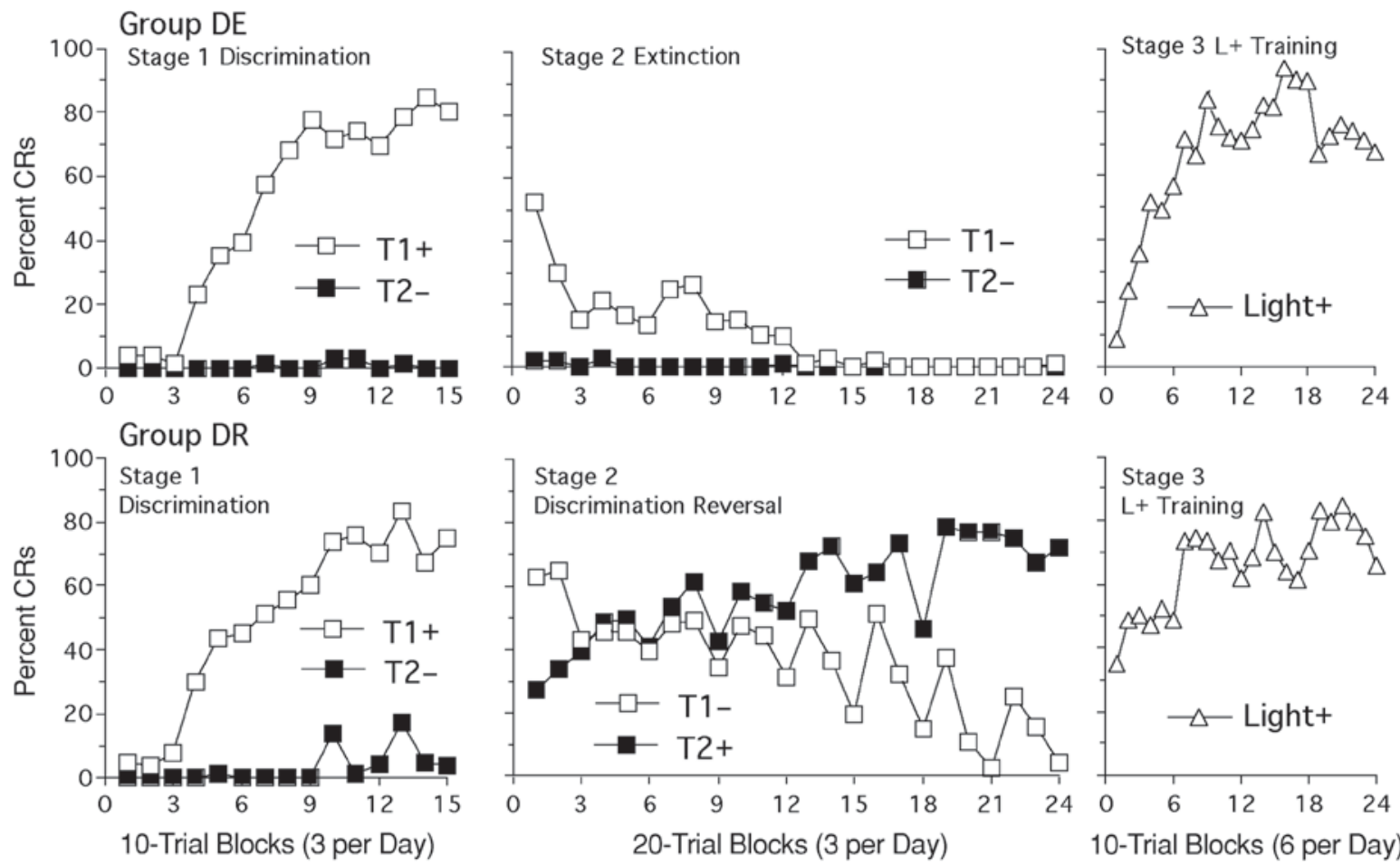

Figure 3. Percentage of CRs in the three successive stages of Experiment 2. Each row of panels shows the results of a different group. In Stage 1 (left panels), both groups received differential conditioning of two tones (T1+, T2-). In Stage 2 (middle panels), Group DE received nonreinforced presentations of the two tones (T1-, T2-), and Group DR received reversal training of the original two-tone discrimination $(\mathrm{T} 1-, \mathrm{T} 2+)$. In Stage 3 (right panels), both groups received reinforced presentations of a light $\mathrm{CS}(+)$. 
.01]. On the last day of discrimination reversal training, all 8 animals showed higher levels of responding to T2 than T1. Among these animals, 4 showed absolutely no responding to $\mathrm{T} 1$.

Stage 3: Cross-modal acquisition. The right-hand panels of Figure 3 show the mean percentage of CRs for both groups plotted in 10-trial blocks across the 4 days of $\mathrm{L}+$ training in Stage 3. Acquisition to the light CS was rapid; both groups achieved a mean level of responding around $40 \%$ CRs ( $\pm 6 \%$ SEM) on the first day of Stage 3. Acquisition of responding to the light CS appeared to be similar in both groups. Any apparent differences between them failed to attain statistical significance $(F<1)$.

Stage 3: Concurrent recovery. Figure 4 shows responding to the tone test trials at the beginning of each $\mathrm{L}+$ training session during Stage 3. At the start of the first day of Stage 3 before any L + trials, Group DE showed no evidence of spontaneous recovery of responding to T1, which had undergone complete extinction in Stage 2. There was also no responding to $\mathrm{T} 2$, which had never been reinforced in Group DE. As CR acquisition to the light proceeded, there was an increase in responding to both tones in Group DE, but more so for T1 than T2. This difference was confirmed by a significant interaction of stimulus $(\mathrm{T} 1 \mathrm{vs.} \mathrm{T} 2) \times$ day $($ linear trend) $[F(1,14)=6.21$,
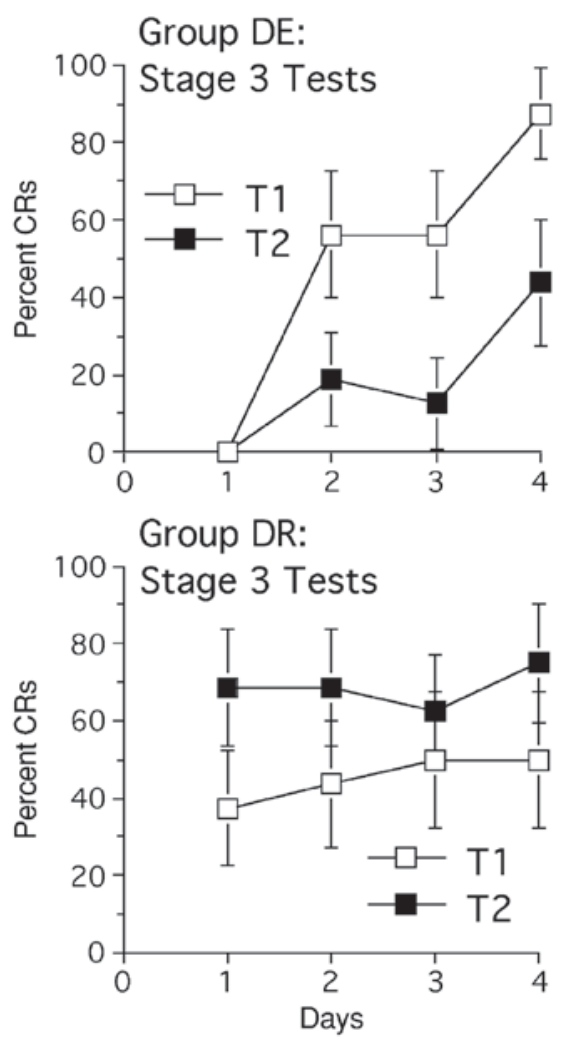

Figure 4. Percentage of CRs on tests of the two tone CSs (T1, T2) as a function of days in Stage 3 of Experiment 2. The tone test trials were always presented at the beginning of each daily training session. The top panel shows the results of Group DE, and the bottom panel shows the results of Group DR. $p<.05]$. By the last day of Stage 3, Group DE showed significantly more responding to $\mathrm{T} 1(M=88 \% \mathrm{CRs}$, $\pm 12 \% S E M)$ than to T2 $(M=44 \% \mathrm{CRs}, \pm 16 \% S E M)$ $[F(1,14)=6.66, p<.05]$.

Whereas Group DE showed significant recovery of responding in Stage 3, Group DR showed levels of responding to T1 and T2 that were consistent with their performance at the end of discrimination reversal in Stage 2. Specifically at the start of Stage 3, Group DE showed $69 \%$ CRs $( \pm 15 \% S E M)$ to T2, which had been reinforced in Stage 2, and 38\% CRs ( $\pm 15 \% S E M)$ to T1, which had undergone extinction training in Stage 2. During subsequent $\mathrm{L}+$ training, responding to $\mathrm{T} 2$ and $\mathrm{T} 1$ rose slightly, more so for T1 than T2. The statistical analysis revealed that across both tones, the linear trend across days was not significant $(F<1)$. However, there was a significant interaction of stimulus (T1 vs. T2) $\times$ day (linear trend) $[F(1,14)=5.75, p<.05]$. Follow-up tests revealed that the difference in responding to T1 versus $\mathrm{T} 2$ was significant at the start of Stage $3[F(1,14)=11.29, p<.01]$, but not at the end of Stage $3[F(1,14)=2.17, p>.10]$. At that point, responding to T1 in Group DR had risen 12 percentage points to $50 \%$ CRs $( \pm 18 \% S E M)$, whereas responding to T1 had risen 6 percentage points to $75 \%$ CRs $( \pm 15 \%$ SEM) .

Comparison between the two groups with regard to recovery of responding to T1 in Stage 3 was hampered by the incomplete extinction of responding to T1 in Group DR in Stage 2. On the first day of Stage 3 before any L+ training, Group DE showed a significantly lower level of responding to T1 $(M=0 \% \mathrm{CRs}, \pm 0 \% S E M)$ than Group DR $(M=38 \%$ CRs, $\pm 15 \%$ SEM $)$. By the start of the fourth day of $\mathrm{L}+$ training, Group DE showed a numerically higher level of responding to T1 $(M=88 \% \mathrm{CRs}$, $\pm 12 \% S E M)$ than Group DR $(M=50 \%$ CRs, $\pm 18 \%$ $S E M)$. However, this difference failed to reach statistical significance $[F(1,14)=2.74, p>.10]$.

\section{Discussion}

The results for Group DE in Experiment 2 replicated those of Group Discrim in Experiment 1. That is, as a result of $\mathrm{L}+$ training, there was considerable recovery of responding to the tone that had previously been paired with the US (T1). The present results also confirmed that during $\mathrm{L}+$ training, there was also an increase in responding to $\mathrm{T} 2$ even though it had previously received only nonreinforced exposure throughout Stages 1 and 2. In Group $\mathrm{DE}$, the use of tone test trials at the start of each session of $\mathrm{L}+$ training helped to illuminate the pattern of recovery as compared to the interspersed tone test trials used in Group Discrim in Experiment 1. Two points are particularly noteworthy. First, on the first day of Stage 3 prior to any $\mathrm{L}+$ trials, Group DE did not show any responding to either T1 or T2, thereby confirming that concurrent recovery is not confounded with spontaneous recovery. Second, responding to $\mathrm{T} 1$ and $\mathrm{T} 2$ at the start of the subsequent days of L + training (Days 2-4 of Stage 3) indicated that concurrent recovery persisted overnight and was independent of any transient aftereffects of the $\mathrm{L}+$ trials. 
With regard to Group DR, the difficulty of obtaining a complete reversal in Stage 2, especially the spontaneous recovery of responding to $\mathrm{T} 1$ at the start of each session, made it difficult to tell whether or not the discrimination reversal had any effect on the level of concurrent recovery to $\mathrm{T} 1$ during $\mathrm{L}+$ training in Stage 3. In Stage 2, the difficulty of extinguishing responding to T1 in Group DR contrasted strongly with the speed of extinction to T1 in Group DE. In Group DR, there appeared to have been considerable generalization of responding to $\mathrm{T} 1$ from the reinforced T2 trials. However, in Stage 1, there was little or no evidence for generalization to $\mathrm{T} 2$ from the reinforced $\mathrm{T} 1$ trials. Thus, the increased intramodal generalization between T1 and T2 in Stage 2 might reflect their shared association with the US. By the same token, in Stage 3, pairings of the light with the same US may have increased cross-modal generalization from the light to the tones.

\section{EXPERIMENT 3}

The results of Experiments 1 and 2 indicate that, allowing for some intramodal generalization, concurrent recovery was largely specific to a CS that had been paired with the US. In addition, the results of Group DR versus Group DE in Experiment 2 suggested that shared associations with a US may provide the basis for increases in generalization among otherwise distinctive CSs. Conversely, in studies of "acquired distinctiveness," generalization between similar CSs has been attenuated by pairing them with different outcomes (Coutureau et al., 2002; Delamater, 1998; Honey \& Hall, 1989, 1991; Honey \& Ward-Robinson, 2002). For example, Delamater (1998) conducted training in which two auditory stimuli (A1, A2) and two visual stimuli (V1, V2) were each paired with one of two types of food outcome (labeled here as + or \#). One group of rats received different outcomes for each stimulus within each modality (e.g., A1+ vs. A2\#, V1+ vs. V2\#). Subsequently, the animals were trained in a simple discrimination in which one stimulus in each modality was reinforced, and the other stimulus was not (e.g., $\mathrm{A} 1+$ vs. A2-). Differential responding in the simple discrimination was acquired faster in this group than in a control group that had received initial training in which the stimuli in each modality were both paired with the same outcome (A1+ and A2+, V1\# and V2\#).

The aim of Experiments $3 \mathrm{~A}$ and $3 \mathrm{~B}$ was to determine whether cross-modal discrimination training in Stage 1 would attenuate subsequent concurrent recovery in Stage 3. The initial discrimination training used distinct consequences (reinforcement vs. nonreinforcement) for a tone versus a light. Experiments $3 \mathrm{~A}$ and $3 \mathrm{~B}$ each contained two groups. One group was given explicit cross-modal discrimination (CMD) training with tone versus light in Stage $1(\mathrm{CSA}+$ vs. CSB -$)$. The second group was given acquisition training with a single stimulus (SST) in Stage 1 $(\mathrm{CSA}+)$. In Stage 2, responding to CSA in both Groups CMD and SST was extinguished. In Stage 3, both groups were given CSB + training and were tested for recovery of responding to CSA.
Experiments $3 \mathrm{~A}$ and $3 \mathrm{~B}$ differed in the number and location of CSA test trials in Stage 3. In Experiment 1, robust concurrent recovery appeared when six CSA test trials were interspersed in each session of CSB + training. In Experiment $3 \mathrm{~A}$, there were $12 \mathrm{CSA}$ test trials interspersed within each session. As will be discussed below, this larger number of CSA test trials appeared to diminish concurrent recovery. In Experiment 3B, there were only four CSA test trials in each session, and, as in Experiment 2 , they were presented at the very beginning of each session before the start of CSB + trials

\section{Method}

Subjects. The subjects were 32 naive female, albino rabbits.

Apparatus and Procedure. Unless otherwise indicated, the apparatus and procedure were identical to those of Experiment 1. In Experiment 3A, the rabbits were randomly assigned to one of two groups $(n=8)$ designated as CMD1 (cross-modal discrimination) or SST1 (single stimulus training) according to the type of training they received in Stage 1. In Experiment 3B, the rabbits were randomly assigned to two corresponding groups designated as Groups CMD2 and SST2, respectively.

In Experiment 3A, Stage 1 lasted for 5 days. During each daily session, Group CMD1 received 30 CS-US pairings (CSA+) intermixed with 30 presentations of a cross-modal CS in the absence of reinforcement (CSB-). For half the animals in Group CMD1, CSA was a $1000-\mathrm{Hz}, 88-\mathrm{dB}$ tone, and CSB was the flashing houselight. For the other half of the animals, this stimulus assignment was reversed. For Group CMD1, the average ITI was $60 \mathrm{sec}$ (range, 50-70 sec). Group SST received 30 CS-US pairings (CSA+) interspersed with 30 "blank" trials with no programmed stimuli. For half the animals in Group SST1, CSA was the tone, and for the other half, CSA was the light. For Group SST1, the average ITI between trials containing a CS was $120 \mathrm{sec}$ (range, 50-210 sec). In Stage 2, which lasted for 7 days, both groups received 60 CSA-alone extinction trials. The average ITI was $60 \mathrm{sec}$ (range, $50-70 \mathrm{sec}$ ). In Stage 3, which lasted for 5 days, both groups received reinforced training with the alternate CS (CSB+). For Group CMD1, CSB was the stimulus that had been presented in Stage 1 in the absence of reinforcement, and for Group SST, CSB was a novel stimulus. On each day, both groups received $60 \mathrm{CSB}+$ trials and 12 nonreinforced test trials of CSA. Each block of six trials had five CSB + trials and one test trial of CSA.

In Experiment 3B, Stages 1 and 2 were identical to Experiment 3A, but Stage 2 lasted for 6 days rather than 7 days. In Stage 3, which lasted for 4 days, both Groups CMD2 and SST2 received only four test trials of CSA, all of which occurred at the very beginning of each session.

\section{Results}

In Experiment 3A, 1 animal in Group CMD1 failed to show extinction in Stage 2. It persisted in responding at levels of more than $50 \%$ CRs throughout all 7 days of extinction, and, hence, its data were removed from the analyses. In Group SST1, 2 animals were removed as a result of injury on the preparation day. In Experiment 3B, 1 animal in Group CMD2 and 1 animal in Group SST2 failed to meet the criterion for acquisition; neither animal showed more than $25 \%$ CRs on any trial block on the 6 days of Stage 1. Thus, the sample size of Group SST1 in Experiment 3A was 6, and all other groups had sample sizes of 7. Figure 5 depicts $\mathrm{CR}$ performance during the three stages of Experiments $3 \mathrm{~A}$ and $3 \mathrm{~B}$ using the final sample sizes. 

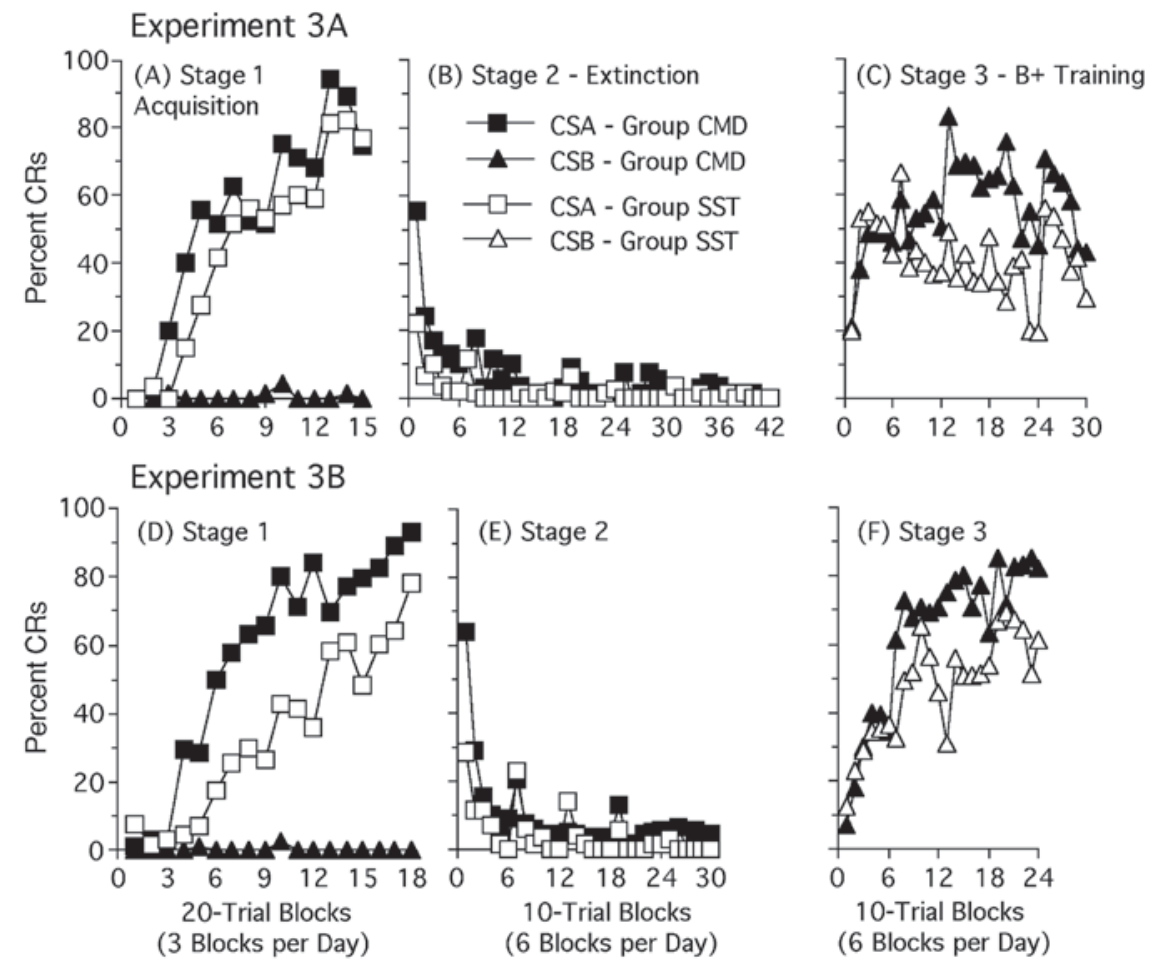

Figure 5. Percentage of CRs across the three successive stages of Experiments $3 \mathrm{~A}$ and $3 \mathrm{~B}$. In Stage 1 (panels A, D), the SST groups received reinforced presentations of a single stimulus (CSA+, open squares), and the CMD groups received differential conditioning (CSA+, solid squares; CSB-, solid triangles). In Stage 2 (panels B, E), all groups received nonreinforced presentations of the previously reinforced stimulus (CSA-). In Stage 3 (panels C, F), the SST groups received reinforced presentations of a novel stimulus $(\mathrm{CSB}+)$, and the $\mathrm{CMD}$ groups received reinforced presentations of the nonreinforced stimulus from Stage $1(\mathrm{CSB}+)$.

Stage 1: Acquisition. The left-hand panels of Figure 5 (panels A, D) show the mean percentage of CRs during acquisition of discriminative responding to CSA + and $\mathrm{CSB}-$ in the CMD groups and acquisition of responding to CSA+ in the SST groups. The curves show that all four groups acquired CRs to CSA+ to levels around $80 \%$ CRs. In Experiment 3B, Group CMD2 appeared to show faster $\mathrm{CR}$ acquisition on CSA + trials than did Group SST2, but this difference was not statistically significant either in overall comparisons between the groups or in interactions with trial blocks [largest $F(1,12)=3.14, p>.10]$. Additionally, as can be readily seen in Figures $5 \mathrm{~A}$ and 5D, the CMD groups acquired significant discriminative responding to $\mathrm{CSA}+$ versus $\mathrm{CSB}-$, which elicited virtually no CRs for Group CMD1 $[F(1,6)=47.36, p<.05]$ or for Group CMD2 $[F(1,6)=37.64, p<.05]$.

Stage 2: Extinction and reversal. The middle panels of Figure 5 (panels B, E) show the course of CR extinction to CSA. By the 6th day of Stage 2, extinction was complete for both groups. The highest mean level of responding in any trial block on the 6th day and thereafter was 6\% CRs $( \pm 2.9 \% S E M)$, which is consistent with the baseline of spontaneous responding in the rabbit NM preparation
(Gormezano, Kehoe, \& Marshall, 1983). Although the CMD groups appeared to show more responding than the SST groups during extinction, neither of these differences was statistically significant either in overall comparisons between the groups or in interactions with trial blocks [largest $F(1,12)=1.62, p>.10]$.

Stage 3: Cross-modal acquisition. The right-hand panels of Figure 5 (panels C, F) show CR acquisition during $\mathrm{CSB}+$ training in Stage 3. Initial acquisition to CSB was rapid in all groups compared with their initial rate of acquisition to CSA in Stage 1. Across the two experiments, the mean levels of responding to CSB on the first day of Stage 3 ranged from $28 \%$ CRs to $45 \%$ CRs. These levels were significantly higher than the mean levels on the first day of Stage 1, which were less than $10 \%$ CRs [smallest $F(1,12)=5.73, p<.05$ ]. This rapid CR acquisition to CSB after initial acquisition to CSA is consistent with previous demonstrations that cross-modal acquisition is facilitated despite responding to CSAs having been thoroughly extinguished (Kehoe et al., 1995; Kehoe, Morrow, \& Holt, 1984; Macrae \& Kehoe, 1999). After the first day of CSB + training, the Groups CMD1 and SST1 in Experiment 3A showed variable responding roughly 
centered about $50 \%$ CRs. In contrast, Groups CMD2 and SST2 showed steady CR acquisition to CSB that reached levels around $70 \%$ CRs.

In the CMD groups in both experiments, the prior nonreinforced exposure to CSB in Stage 1 did not appear to interfere with CR acquisition to CSB. In fact, the CMD groups tended to show higher levels of responding to CSB than did the SST groups, for which CSB was a novel stimulus. However, the apparent differences between the groups in either experiment were not significant in either overall comparisons between groups or in interaction with trial blocks [largest $F(1,12)=2.35, p>.10$ ]

Stage 3: Concurrent recovery. Figure 6 shows the results of tests for concurrent recovery of responding to CSA during Stage 3 in both experiments. In Experiment 3A, Groups CMD1 and SST1 showed only weak recovery. The most recovery was seen on the first day of $\mathrm{CSB}+$ training; responding on CSA trials reached a mean level of $31 \%$ CRs ( $\pm 16 \%$ SEM) in Group CMD1 and 23\% CRs $( \pm 10 \%$ SEM) in Group SST1. Thereafter, responding to CSA declined. Any apparent differences between the groups did not even approach statistical significance $[F(1,11)=1.63, p>.10]$.

In Experiment 3B, there was stronger recovery in both Groups CMD2 and SST2. Specifically, on the first CSA tests before any CSB + trials, there was no spontaneous recovery of responding. Thereafter, responding to CSA rose in both groups. After 1 day of CSB + pairings, the mean CR likelihood at the beginning of Day 2 reached a level around $57 \%$ CRs $( \pm 14 \%$ SEM) in Group CMD2 and $25 \%$ CRs $( \pm 12 \%$ SEM) in Group SST2. There was a significant difference in responding between the first day and subsequent days of Stage $3[F(1,12)=24.28, p<$ $.05]$, but any apparent differences between the two groups were not significant [larger $F(1,12)=3.07, p>.10]$.

The nonreinforced exposure to CSB in Stage 1 in the CMD groups failed to reduce the level of concurrent recovery to CSA. Parallel to what was seen in CR acquisition to CSB in Stage 3, the CMD groups in both experiments appeared to show more responding to CSA than their corresponding SST groups. However, these apparent differences between groups were not statistically significant in either overall comparisons or in interactions with trial blocks [largest $F(1,12)=3.07, p>.10]$.

\section{Discussion}

The main finding of Experiments $3 \mathrm{~A}$ and $3 \mathrm{~B}$ was that, despite prior cross-modal discrimination training between the CSA and CSB, concurrent recovery of responding to $\mathrm{CSA}$ occurred during $\mathrm{CSB}+$ training. In fact, in both experiments, the level of recovery in the CMD groups was numerically greater than in SST groups. In absolute terms, Group CMD2 in Experiment 3B showed much the same level of recovery to CSA as seen in Group Discrim in Experiment 1 and Group DE in Experiment 2. All three of these groups showed levels around $60 \%$ CRs despite having different initial training histories. In conclusion, concurrent recovery appears to be robust in the face of discrimination training, which might have reduced any emergent cross-modal generalization.

The recovery in Experiment 3A was weak and transient compared to that seen in Experiment 3B, as well as in the other experiments in this series and in previous investigations (Macrae \& Kehoe, 1999; Weidemann \& Kehoe, 2003, 2004). The weakness of recovery in Experiment 3B may have occurred for two reasons. First, for unknown reasons, the asymptotic acquisition on $\mathrm{CSB}+$ trials was lower and more variable than usual. Second, the number of CSA test trials (12 per session) was much larger than that used in other experiments. In particular, Experiment 1 contained six tests of $\mathrm{T} 1$ interspersed during each CSB + session. Experiment 2 contained only two tests of T1 at the start of each session, and Experiment 3B contained four tests of CSA at the start of each session.

\section{GENERAL DISCUSSION}

The present experiments resulted in two key findings. First, concurrent recovery appeared after a variety of initial training conditions. That is, concurrent recovery of extinguished responding appeared to approximately an equal degree after single-stimulus training of the target
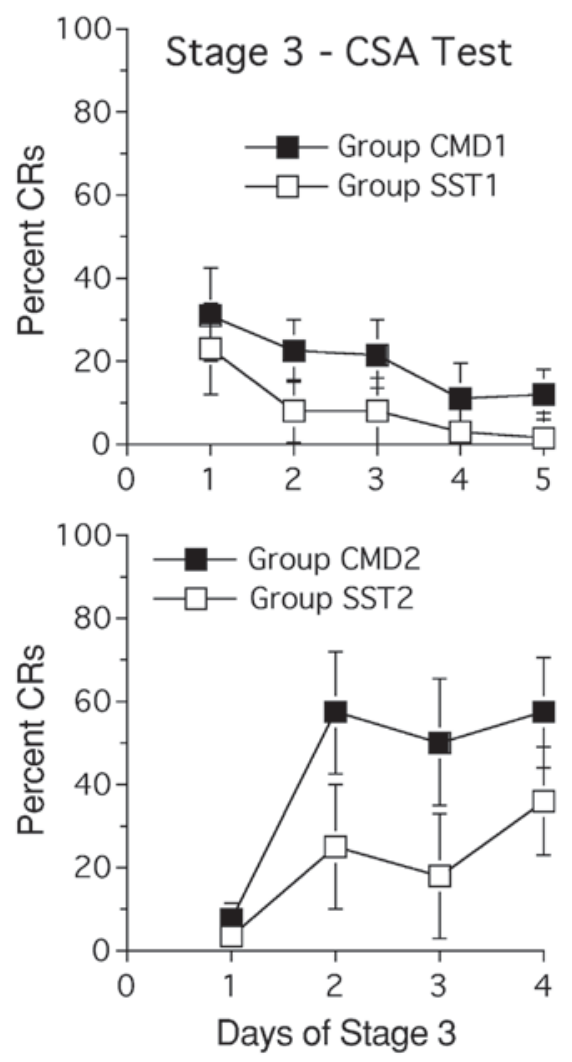

Figure 6. Percentage of CRs on tests of the extinguished stimulus (CSA) in the SST and CMD groups in Experiment 3 as a function of days in Stage 3. In Experiment 3A, the CSA test trials were interspersed among the CSB-US trials, and in Experiment 3B, the CSA test trials were presented at the start of each daily session. 
stimulus (Group Single in Experiment 1, Groups SST1 and SST2 in Experiment 3), partial reinforcement of the target stimulus (Group Pseudo in Experiment 1), intramodal discrimination training (Group Discrim in Experiment 1, Group DE in Experiment 2), and even crossmodal discrimination training using the stimulus (CSB) ultimately used to induce concurrent recovery (Group CMD2 in Experiment 3). Second, concurrent recovery showed strong but not exclusive specificity to the target stimulus. That is to say, Experiments 1 and 2 demonstrated that, following reinforced training and extinction of responding to the target tone (T1), the final stage of training with the light stimulus yielded strong recovery of responding to test presentations of $\mathrm{T} 1$ but also moderate levels of responding to a second tone (T2) that had either been a novel stimulus (Group Single in Experiment 1) or a previously nonreinforced stimulus (Group Discrim in Experiment 1, Group DE in Experiment 2).

At an empirical level, the primary aim of the present experiments was to determine the stimulus specificity of concurrent recovery and, secondarily, to discover whether the degree of specificity would be influenced by initial discrimination training. As summarized in the previous paragraph, concurrent recovery was strong but not exclusive to the target stimulus (T1 in Experiments 1 and 2). There was moderate but discernible responding to a test stimulus (T2 in Experiments 1 and 2), which was about the same regardless of whether it had previously been subjected to nonreinforcement in initial discrimination training. However, the source of responding to T2 is not entirely clear. Given the results of previous studies of generalization, at least a portion of responding to T2 probably reflected intramodal generalization. However, as this intramodal generalization did not appear during initial training but only during final testing during $\mathrm{L}+$ training, intramodal generalization may have been enhanced in a learning-dependent manner.

With respect to the three hypothetical possibilities raised in the introduction, a process of elimination suggests that the first possibility makes the largest contribution to concurrent recovery. That is, concurrent recovery appears to be mediated primarily by associative linkages shared by the CSs. The second conceivable outcome was that reinforced training with orthogonal stimuli would cause widespread generalization within their modalities. According to this hypothesis, initial discrimination training between the two tones should have reduced any nonspecific crossmodal generalization and thereby increased the specificity of concurrent recovery. Contrary to this hypothesis, the results of Experiment 1 indicated that the degree of specificity is relatively constant regardless of whether initial training contained only a single reinforced stimulus $(\mathrm{T} 1+)$ or discrimination training $(\mathrm{T} 1+\mathrm{vs} . \mathrm{T} 2-)$. The third conceivable outcome was that ambiguity in the total set of stimulus-reinforcer relationships in one modality could reduce the overall level of concurrent recovery during later training with an orthogonal stimulus. Contrary to this hypothesis, the level of recovery appeared to be the same regardless of whether initial training contained unambiguous single-stimulus training or some degree of ambiguity, including intramodal discrimination training, partial reinforcement, or even cross-modal discrimination training.

At a theoretical level, the question becomes what shared linkages could explain concurrent recovery as a learningdependent form of cross-modal generalization. A review of the conditioning literature indicates that there are four basic approaches. First and historically, there has been a responsemediated form of learning-dependent generalization. Second and more recently, there have been reinforcermediated forms of learning-dependent generalization. Third, there is the possibility that there is a context-mediated form of learning-dependent generalization. As we discuss below, all three of these approaches can account superficially for concurrent recovery, but each has problems in explaining other well-established types of savings and recovery after extinction seen in the rabbit NM preparation. However, as a fourth possibility, shared connections in a layered neural network may be able to explain both concurrent recovery and previous findings.

Response-mediated generalization. Miller and Dollard (1941, pp. 62-65) proposed a theory of acquired equivalence in which increased generalization between otherwise distinctive physical stimuli is mediated by acquisition of a common response. In experiments used to illustrate this approach (e.g., Johns \& Williams, 1998), an appetitive approach behavior is conditioned to two different stimuli, CSA and CSB, using a common reward (i.e., food). To test whether this common response can mediate generalization between the two CSs, CSA and its approach behavior were paired with a footshock punisher that elicits aversive behavior that mechanically conflicts with the approach behavior. CSA and, more importantly, the approach behavior (strictly speaking, its sensory consequences) become cues for the aversive behavior. When CSB is tested, it evokes the original approach behavior that in turn elicits the conflicting aversive behavior as measured by suppression of the approach behavior during CSB.

A response-mediation theory cannot explain concurrent recovery and other forms of savings after extinction because they occur when CSA and CSB do not in fact elicit a common response. When CSB is introduced in Stage 3 and paired with the US, the overt CR to CSA was abolished. A response-mediation account, however, might be defended by the contention that the extinction does not abolish the excitatory CR but instead results in the establishment of an unseen, competing, inhibitory behavior that conflicts with the overt CR. Although this theoretical move permits CSA and CSB to still share the excitatory $\mathrm{CR}$, the assumption of an inhibitory response creates further difficulties for a response-mediation account. First, the assumption of an unobserved, hypotheti$\mathrm{cal}$, inhibitory CR is special pleading that contravenes the original peripheralistic nature of the theory, which relies on mechanical conflicts between alternative behaviors. 
Second, if CSA is assumed to have acquired an inhibitory response alongside the excitatory $\mathrm{CR}$, then such an amended theory would predict slow acquisition of CRs to CSB because it should elicit the inhibitory response as well as the excitatory CR.

This second prediction is incorrect for the rabbit NM preparation. Cross-modal acquisition to CSB is more rapid than naive acquisition even when the $\mathrm{CR}$ to the original CSA has been thoroughly extinguished (Kehoe et al., 1995; Kehoe et al., 1984; Macrae \& Kehoe, 1999; Weidemann \& Kehoe, 2003). This finding was replicated in the present results: In Experiments $3 \mathrm{~A}$ and 3B, crossmodal acquisition to CSB in Stage 3 was more rapid than acquisition to CSA in Stage 1, despite the complete extinction of responding to CSA in Stage 2. Furthermore, retraining using the original CSA has consistently produced rapid reacquisition in the rabbit NM preparation rather than the slow reacquisition that would be predicted by the response-mediation account (Macrae \& Kehoe, 1999; Napier et al., 1992; Weidemann \& Kehoe, 2003).

Reinforcer-mediated generalization. To avoid the problems faced by response-mediation theory, there have been attempts to explain learning-dependent generalization effects by allowing for mediation via shared linkages from CSs to either representations of the reinforcer (Honey \& Hall, 1989) or reinforcer expectancies (Overmier \& Lawry, 1979; Peterson \& Trapold, 1980). In the case of the present results, such accounts would contend that initial acquisition training produces a CSA $\rightarrow$ US linkage. During extinction training, CSA would retrieve the US representation, which would then become associated with a representation of nonreinforcement arising, for example, from a violation of the reinforcer expectancy. Hence, there would be a CSA $\rightarrow$ US $\rightarrow$ noUS chain of linkages. However, this logic yields the same counterfactual predictions regarding reacquisition and cross-modal acquisition as seen in the amended response-mediation theory. In the case of cross-modal training, there would be slow acquisition rather than rapid acquisition of CRs to CSB, because CSB would retrieve the US $\rightarrow$ noUS linkage. Eventually, CRs would emerge because either (1) the US $\rightarrow$ noUS linkage would fade in the face of US pairings with CSB, or (2) the representation of noUS itself would become a signal for the US, thus producing a chain of associations: $\mathrm{CSB} \rightarrow \mathrm{US} \rightarrow$ noUS $\rightarrow \mathrm{US}$. For these reasons, concurrent recovery of responding to CSA would be predicted to appear very belatedly, either as a result of the fading of the US $\rightarrow$ noUS linkage or acquisition of a US $\rightarrow$ noUS $\rightarrow$ US linkage.

Context-mediated generalization. The CSA-US pairings and CSB-US pairings could share a context that mediates a recovery of CRs to CSA and other savings after extinction. However, it is not clear exactly how a shared context would do so. Operationally, the reintroduction of the US during CSB-US pairings could reinstate a key component of the context for the CR to CSA (Bouton \& Nelson, 1998; Capaldi, 1994). However, research in our laboratory has not revealed that reinstatement occurs in the rabbit NM preparation (Napier et al., 1992; Weide- mann \& Kehoe, 2004). Even repeated presentations of the US, which could cause reacquisition of context-US associations (Brandon \& Wagner, 1991; Wagner \& Brandon, 1989), do not result in discernible reinstatement of the CR to an extinguished CS (Weidemann \& Kehoe, 2004).

As an alternative hypothesis, context-CSA and contextCSB associations may mediate generalization of responding from the CSB-US pairings to CSA in Stage 3. If one postulates a bidirectional within-compound association, then it is conceivable that CSB's excitatory strength could generalize via the contextual associations to CSA (i.e., $\mathrm{CSB} \rightarrow$ context $\rightarrow$ CSA; cf. Blaisdell et al., 1998; Honey \& Ward-Robinson, 2002). Unfortunately, the available evidence does not support this hypothesis, at least for conditioning in the rabbit NM preparation. Specifically, Weidemann and Kehoe (2004) conducted CSB-US pairings prior to the initial CSA-US pairings and CSA- extinction training. According to the proposed hypothesis, CSB-US pretraining should have strengthened its context-CSB association, which in turn should have enhanced concurrent recovery. In fact, the CSB-US pretraining significantly reduced the ability of later CSB-US pairings to produce concurrent recovery of extinguished responses to CSA. Moreover, if shared context-CS associations play a major role in concurrent recovery, then the initial discrimination training in Experiments 1 and 2 should have established equally strong context associations for both the reinforced tone (context-T1) and nonreinforced tone (context-T2). Subsequently, the excitation should have flowed equally from the light stimulus through the light-context linkage to both T1 and T2. Hence, this hypothesis cannot explain the specificity in concurrent recovery to $\mathrm{T} 1$ and not $\mathrm{T} 2$. Given that there was some responding to $\mathrm{T} 2$, there remains the possibility that some of the responding to $\mathrm{T} 1$ and $\mathrm{T} 2$ might have arisen via context-CS associations.

Connectionist models of generalization. Connectionist models using multiple layers provide a mediational mechanism in which otherwise distinctive stimuli can acquire shared linkages (Gluck \& Myers, 1993, 1997; Kehoe, 1988; Rumelhart, Hinton, \& Williams, 1986; Schmajuk \& DiCarlo, 1992). With a generic architecture and common learning rule, such networks can explain the full range of cross-modal and recovery phenomena that have been observed with the rabbit NM preparation (Kehoe, 1988; Weidemann \& Kehoe, 2004). Figure 7 shows a schematic for a network. There are three sensory inputs-specifically, Tone 1 , Tone 2, and light - that project to three sensory units designated as $\mathrm{T} 1, \mathrm{~T} 2$, and $\mathrm{L}$, respectively. These primary projections are indicated by arrows with unbroken lines. In addition, the model allows for partially overlapping encoding fields for the two-tone stimuli by cross connections, as indicated by arrows with dotted lines (cf. Desmond, 1990). This overlap in the encoding of the two tones allows for any contribution of unlearned intramodal generalization. The second layer contains connections between the sensory encodings of the exterior inputs and the three adaptive, hidden units (X, Y, Z). Each sensory encoding unit projects to all three of these units. In the third layer, these hidden units project to another adaptive 


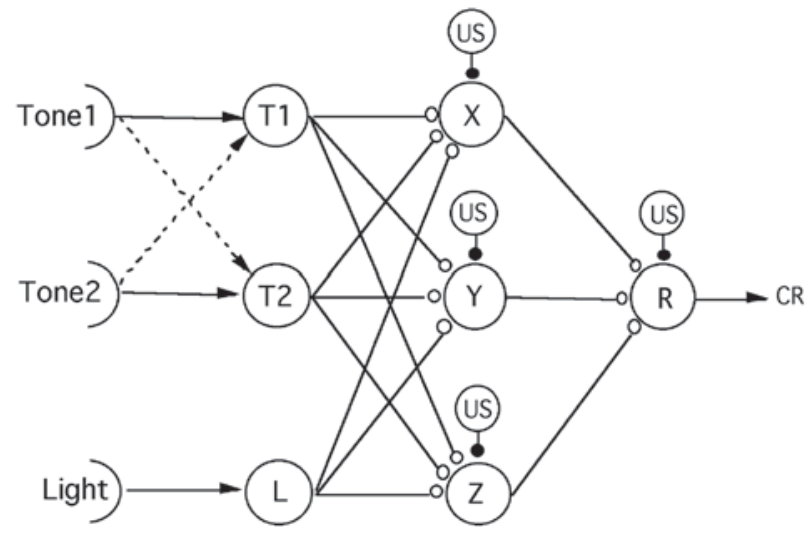

Figure 7. A connectionist model for acquisition, extinction, and savings in classical conditioning. It contains four sensory inputs (US, Tone 1, Tone 2, Light), three neuron-like sensory units (T1, $T 2, L)$, and four adaptive units $(X, Y, Z, R)$. There are fixed excitatory connections between the Tone 1 , Tone 2 , and Light sensory inputs and their respective neuron-like units T1, T2, and L (solid lines with arrows) and between the Tone 1 sensory input and the T2 unit and the Tone 2 sensory input and the T1 unit (dotted lines). There are plastic excitatory connections between the CS units $(T 1, T 2, L)$ and the $X, Y$, and $Z$ intermediate units, and between the $X, Y$, and $Z$ units and the $R$ unit.

unit $(\mathrm{R})$ in the output layer of the model, which generates the observable response. To enable associative changes to the connections within the network, the US provides a "teacher" input that triggers the X, Y, Z, and R units on reinforced trials. ${ }^{1}$ The basic learning rule for each connection is the same as used in Rescorla and Wagner's (1972) model, which has been widely adapted in neural network models of classical conditioning (Kehoe, 1988; Sutton \& Barto, 1981; Vogel, Castro, \& Saavedra, 2004). (See the Appendix for the mathematical details of the model, its assumptions, and subsequent simulations.)

In this network, there is the potential for the acquisition of multiple, parallel linkages in each layer when a CS is paired with the US. For example, if reinforced training was conducted with Tone 1, there would first be strengthening of T1's exterior connections (T1-X, T1-Y, T1-Z). As these connections become strong enough to activate the hidden units, their connections with the $\mathrm{R}$ unit would become eligible for strengthening (X-R, Y-R, Z-R). ${ }^{2}$ Once these latter connections were strengthened, the CS would elicit overt CRs.

Among other things, this network can explain the learningdependent generalization between tone and light seen by Schreurs and Kehoe (1987). According to the model, the handful of initial pairings of one CS (e.g., T1) with the US would have partially strengthened the exterior connections (T1-X, T1-Y, T1-Z), but they would not activate the hidden units strongly enough to allow the interior connections to be strengthened. When more extensive training was conducted with the second CS (e.g., L), its exterior connections (L-X, $\mathrm{L}-\mathrm{Y}, \mathrm{L}-\mathrm{Z}$ ) would be strengthened, and, more importantly, the interior connections (X-R, Y-R, Z-R) would also be strength- ened. As these interior connections were strengthened, test trials with the original CS (T1) would be able to elicit some CRs because the exterior connections could weakly activate the hidden units and capitalize on the strengthened interior connections (X-R, Y-R, Z-R).

The same layered structure can also explain the considerable savings that are seen after extinction of the CR in the rabbit NM preparation, in particular, rapid reacquisition of the CR to the extinguished CS and the rapid acquisition of CRs to a new CS from a different modality (Kehoe et al., 1984; Macrae \& Kehoe, 1999; Weidemann \& Kehoe, 2003). At the beginning of extinction with an established CS, both the exterior and interior connections would start to diminish. As the exterior connections, however, become too weak to activate the hidden unit, the interior connections would be protected from further extinction, because they would not be receiving input from the hidden unit or from the absent US. Provided that the rate of decline in the interior connections is about the same or less than that of the exterior connections, a considerable portion of the interior connections' strength would be preserved. Thus, this strength would be available when any exterior connections were strengthened during any subsequent reinforced training with any CS (Kehoe, 1988; Weidemann \& Kehoe, 2004).

As can now be seen, a layered network model can explain both the learning-dependent generalization seen in acquisition (Schreurs \& Kehoe, 1987) and the savings seen after extinction with only simple parametric assumptions, specifically, that the learning rates for all the connections are equal. Surprisingly, the learning-dependent generalization seen after extinction in the form of concurrent recovery seems to require a more complex set of parametric assumptions. The problem that concurrent recovery poses for the proposed layered network arises from the strong assumption that the sensory encodings for stimuli from different modalities are entirely isolated from each other, namely, the light (L) versus the tone stimuli (T1,T2). That is, there is no inbuilt possibility of generalization between them as there is between stimuli from the same modality $(\mathrm{T} 1, \mathrm{~T} 2)$. Previously, this assumption has been required by repeated failures to detect any unlearned generalization between the visual and auditory CSs in the rabbit NM preparation (Kehoe, 1992; Kehoe \& Holt, 1984; Macrae \& Kehoe, 1999; Schreurs \& Kehoe, 1987; Weidemann \& Kehoe, 2004). By the same token, the exterior connections for the light versus tone stimuli are specific to those stimuli. Thus, in Stage 3 of the present experiments, there is no way that the acquisition of the $\mathrm{L}-\mathrm{X}, \mathrm{L}-\mathrm{Y}$, and $\mathrm{L}-\mathrm{Z}$ connections can influence the ability of test presentations of T1 or T2 to activate the X, Y, or Z units.

Simulations were first conducted with all the learning rates set to the same value. Across a wide range of values, it proved impossible for the model to produce any evidence of substantial concurrent recovery, even though it could reproduce rapid reacquisition after extinction, learning-dependent cross-modal generalization in acquisition, and facilitation of cross-modal acquisition after 
extinction, as had previous versions of this model (Kehoe, 1988). Recently, Weidemann and Kehoe (2004) have proposed that concurrent recovery can be reproduced if the different sensory units are assumed to each favor a particular hidden unit. For example, the T1-X connection may change more rapidly than the $\mathrm{T} 1-\mathrm{Y}$ or $\mathrm{T} 1-\mathrm{Z}$ connections, whereas the $\mathrm{L}-\mathrm{Z}$ connection may change more rapidly than the $\mathrm{L}-\mathrm{X}$ or $\mathrm{L}-\mathrm{Y}$ connections.

To test this idea, a series of simulations were conducted in which the learning rates for exterior connections were manipulated. By using the Rescorla-Wagner formula for each unit, there were in fact two parameters that could be varied. One is related to the CS inputs $(\alpha)$, and one is related to the US input $(\beta)$. The simulations revealed that some degree of concurrent recovery could be produced whenever (1) each sensory input favored a particular hidden unit-that is, the $\alpha$ parameter for the T1-X, T2-Y, and $\mathrm{L}-\mathrm{Z}$ connections was higher than that of the T1-Y, $\mathrm{T} 1-\mathrm{Z}, \mathrm{T} 2-\mathrm{X}, \mathrm{T} 2-\mathrm{Z}, \mathrm{L}-\mathrm{X}$, and $\mathrm{L}-\mathrm{Y}$ connections (e.g., $\alpha=$ .20 versus $\alpha=.07$ ) - and (2) the $\beta$ parameter was higher when the US was present $\left(\beta_{\text {acq }}=.33\right)$ than when it was absent $\left(\beta_{\text {ext }}=.04\right)$ for all connections. Throughout these simulations, the $\alpha$ parameter for the interior connections ( $\mathrm{X}-\mathrm{R}, \mathrm{Y}-\mathrm{R}, \mathrm{Z}-\mathrm{R}$ ) was held constant at the higher value $(\alpha=.20)$.

When this pattern of parameters was used, initial simulated pairings of Tone 1 with the US would produce a strong $\mathrm{T} 1-\mathrm{X}$ connection and modest $\mathrm{T} 1-\mathrm{Y}$ and $\mathrm{T} 1-\mathrm{Z}$ connections. Consequently, the $\mathrm{X}-\mathrm{R}$ connection would be stronger the $\mathrm{Y}-\mathrm{R}$ and $\mathrm{Z}-\mathrm{R}$ connections. During subsequent extinction with Tone 1, all three of the exterior connections would decline. However, for the T1-Y and T1-Z connections, the low values of both their $\alpha$ and $\beta_{\text {ext }}$ parameters would combine multiplicatively to cause only small losses in those connections. Subsequently, during reinforced training with the light, the $\mathrm{L}-\mathrm{Z}$ and, hence, the $\mathrm{Z}-\mathrm{R}$ connections would increase in strength. Hence, the residual T1-Z connection would enable a Tone 1 test to access the growing $Z-R$ connection, thus yielding substantial recovery of responding to Tone 1 . In the case of Groups Discrim and DE, the overlapping encodings of Tone 1 and Tone 2 would allow a Tone 2 input some access to the T1-Z-R linkages, which would produce some responding to Tone 2 as was seen in the present experiments (see Appendix A for these simulations).

Conclusion. Although we have made a case here for a specific neural network model, it can be viewed as mathematical formalism that can accommodate a wide variety of constructions (Kehoe \& White, 2002; Vogel et al., 2004). Although the present model does not include any role for contextual variables, there is nothing to prevent the addition of contextual inputs and an elaboration of the learning rules to accommodate them (cf. Brandon, Vogel, \& Wagner, 2003; Wagner \& Brandon, 1989). However, a layered network model is more than just a mathematical formalism. The other mediational models assume that the basic learning mechanism relies on a single, core associa- tive linkage, either a CS-CR or CS-US linkage, which is supplemented by other associative mechanisms. In contrast, the layered network model assumes that $\mathrm{CR}$ acquisition always relies on a sequence of at least two associative linkages, and perhaps more (Cohen, 1984). This postulation of sequential linkages has precedent. In particular, it has a family resemblance to attentional models (Lubow, Weiner, \& Schnur, 1981; Sutherland \& Mackintosh, 1971), which also assume that basic response acquisition entails two stages of learning. From their perspective, the exterior layer can be construed as the mechanism for acquisition of the attentional response to a specific CS, and the interior layer can be construed as the acquisition of a specific response assignment.

\section{REFERENCES}

Blaisdell, A. P., Bristol, A. S., Gunther, L. M., \& Miller, R. R. (1998). Overshadowing and latent inhibition counteract each other: Support for the comparator hypothesis. Journal of Experimental Psychology: Animal Behavior Processes, 24, 335-351.

Bouton, M. E., \& Nelson, J. B. (1998). The role of context in classical conditioning: Some implications for cognitive behavior therapy. In W. O'Donohue (Ed.), Learning and behavior therapy (pp. 59-84). Boston: Allyn \& Bacon.

Brandon, S. E., Vogel, E. H., \& Wagner, A. R. (2003). Stimulus representation in SOP: I. Theoretical rationalization and some implications. Behavioural Processes, 62, 5-25.

Brandon, S. E., \& Wagner, A. R. (1991). Modulation of a discrete Pavlovian conditioned reflex by a putative emotive Pavlovian conditioned stimulus. Journal of Experimental Psychology: Animal Behavior Processes, 17, 299-311.

CAPAldi, E. J. (1994). The sequential view: From rapidly fading stimulus traces to the organization of memory and the abstract concept of number. Psychonomic Bulletin \& Review, 1, 156-181.

CoHEN, D. H. (1984). Identification of vertebrate neurons modified during learning: Analysis of sensory pathways. In D. L. Alkon \& J. Farley (Eds.), Primary neural substrates of learning and behavioral change (pp. 129-154). New York: Cambridge University Press.

Coutureau, E., Killcross, A. S., Good, M., Marshall, V. J., WardRobinson, J., \& Honey, R. C. (2002). Acquired equivalence and distinctiveness of cues: II. Neural manipulations and their implications. Journal of Experimental Psychology: Animal Behavior Processes, 28, 388-396.

Delamater, A. R. (1998). Associative mediational processes in the acquired equivalence and distinctiveness of cues. Journal of Experimental Psychology: Animal Behavior Processes, 24, 467-482.

DESMOND, J. E. (1990). Temporal adaptive responses in neural models: The stimulus trace. In M. Gabriel \& J. W. Moore (Eds.), Learning and computational neuroscience (pp. 421-456). Cambridge, MA: MIT Press.

Gabriel, M., Wheeler, W., \& Thompson, R. F. (1973). Multiple-unit activity of the rabbit cerebral cortex in single-session avoidance conditioning. Physiological Psychology, 1, 45-55.

Garcia, K. S., Mauk, M. D., Weidemann, G., \& Kehoe, E. J. (2003). Covariation of alternative measures of responding in rabbit (Oryctolagus cuniculus) eyeblink conditioning during acquisition training and tone generalization. Behavioral Neuroscience, 117, 292-303.

Gluck, M. A., \& Myers, C. E. (1993). Hippocampal mediation of stimulus representation: A computational theory. Hippocampus, $\mathbf{3}$, 491-516.

GlucK, M. A., \& Myers, C. E. (1997). Psychobiological models of hippocampal function in learning and memory. Annual Review of Psychology, 48, 481-514.

Gormezano, I. (1966). Classical conditioning. In J. B. Sidowski (Ed.), Experimental methods and instrumentation in psychology (pp. 385420). New York: McGraw-Hill. 
Gormezano, I., \& GibBs, C. M. (1988). Transduction of the rabbit's nictitating membrane response. Behavior Research Methods, Instruments, \& Computers, 20, 18-21.

Gormezano, I., Kehoe, E. J., \& Marshall, B. S. (1983). Twenty years of classical conditioning research with the rabbit. In J. M. Sprague \& A. N. Epstein (Eds.), Progress in psychobiology and physiological psychology (Vol. 10, pp. 197-275). New York: Academic Press.

HALL, G. (1996). Learning about associatively activated stimulus representations: Implications for acquired equivalence and perceptual learning. Animal Learning \& Behavior, 24, 233-255.

HARris, R. J. (1994). ANOVA: An analysis of variance primer. Itasca, IL: F. E. Peacock.

Honey, R. C., \& Hall, G. (1989). Acquired equivalence and distinctiveness of cues. Journal of Experimental Psychology: Animal Behavior Processes, 15, 338-346.

Honey, R. C., \& Hall, G. (1991). Acquired equivalence and distinctiveness of cues using sensory-preconditioning procedure. Quarterly Journal of Experimental Psychology, 43B, 121-135.

Honey, R. C., \& WARD-Robinson, J. (2002). Acquired equivalence and distinctiveness of cues: I. Exploring a neural network approach. Journal of Experimental Psychology: Animal Behavior Processes, 28, 378-387.

Johns, K. W., \& Williams, D. A. (1998). Acquired equivalence learning with antecedent and consequent unconditioned stimuli. Journal of Experimental Psychology: Animal Behavior Processes, 24, 3-14.

KeHOE, E. J. (1988). A layered network model of associative learning: Learning to learn and configuration. Psychological Review, 95, 411-433.

KeHOE, E. J. (1992). Versatility in conditioning: A layered network model. In D. S. Levine \& S. J. Levin (Eds.), Motivation, emotion and goal direction in neural networks (pp. 63-90). Hillsdale, NJ: Erlbaum.

Kehoe, E. J., \& Holt, P. E. (1984). Transfer across CS-US intervals and sensory modalities in classical conditioning in the rabbit. Animal Learning \& Behavior, 12, 122-128.

Kehoe, E. J., Horne, A. J., \& Macrae, M. (1995). Learning to learn: Real-time features and a connectionist model. Adaptive Behavior, 3, 235-271

Kehoe, E. J., \& Macrae, M. (2002). Fundamental behavioral methods and findings in classical conditioning. In J. W. Moore (Ed.), A neuroscientist's guide to classical conditioning (pp. 171-231). New York: Springer.

Kehoe, E. J., Morrow, L. D., \& Holt, P. E. (1984). General transfer across sensory modalities survives reductions in the original conditioned reflex in the rabbit. Animal Learning \& Behavior, 12, 129-136.

Kehoe, E. J., \& White, N. E. (2002). Extinction revisited: Similarities between extinction and reductions in US intensity in classical conditioning of the rabbit's nictitating membrane response. Animal Learning \& Behavior, 30, 96-111.

Lubow, R. E., Weiner, I., \& Schnur, P. (1981). Conditioned attention theory. In G. H. Bower (Ed.), The psychology of learning and motivation (Vol. 15, pp. 1-49). San Diego, CA: Academic Press.

Macrae, M., \& Kehoe, E. J. (1999). Savings after extinction in conditioning of the rabbit's nictitating membrane response. Psychobiology, 27, 85-94.

Marshall-Goodell, B., Schreurs, B. G., \& Gormezano, I. (1982). Ruler vs. the Apple II/FIRST system analysis of analog signals in classical conditioning. Behavior Research Methods \& Instrumentation, 14, 519-525.

Miller, N. E., \& Dollard, J. C. (1941). Social learning and imitation. New Haven, CT: Yale University Press.

Mitchell, D. S. (1974). Conditional responding and intertrial-interval variability in classical conditioning of the rabbit (Oryctolagus cuniculus). Journal of Comparative \& Physiological Psychology, 87, 73-79.

Moore, J. W. (1972). Stimulus control: Studies of auditory generalization in rabbits. In A. H. Black \& W. F. Prokasy (Eds.), Classical conditioning II: Current research and theory (pp. 206-230). New York: Appleton-Century-Crofts.

Napier, R. M., Macrae, M., \& Kehoe, E. J. (1992). Rapid reacquisition in conditioning of the rabbit's nictitating membrane response.
Journal of Experimental Psychology: Animal Behavior Processes, 18, 182-192.

O'Brien, R. G., \& KAISER, M. K. (1985). MANOVA method for analyzing repeated measures designs: An extensive primer. Psychological Bulletin, 97, 316-333.

Overmier, J. B., \& LaWry, J. A. (1979). Pavlovian conditioning and the mediation of behavior. In G. H. Bower (Ed.), The psychology of learning and motivation (Vol. 13, pp. 1-55). New York: Academic Press.

PAVlov, I. P. (1927). Conditioned reflexes: An investigation of the physiological activity of the cerebral cortex (G. V. Anrep, Trans.). London: Oxford University Press.

Peterson, G. B., \& Trapold, M. A. (1980). Effects of altering outcome expectancies on pigeon's delayed conditional discrimination performance. Learning \& Motivation, 11, 267-288.

RATClifF, R. (1990). Connectionist models of recognition memory: Constraints imposed by learning and forgetting functions. Psychological Review, 97, 285-308.

Rescorla, R. A., \& Wagner, A. R. (1972). A theory of Pavlovian conditioning: Variations in the effectiveness of reinforcement and nonreinforcement. In A. H. Black \& W. F. Prokasy (Eds.), Classical conditioning II: Current research and theory (pp. 64-99). New York: Appleton-Century-Crofts

Rumelhart, D. E., Hinton, G. E., \& Williams, R. J. (1986). Learning representations by back-propagating errors. Nature, 323, 533-536.

Scandrett, J., \& GormeZano, I. (1980). Microprocessor control and A/D data acquisition in classical conditioning. Behavior Research Methods \& Instrumentation, 12, 120-125.

Schmajuk, N. A., \& DiCarlo, J. J. (1992). Stimulus configuration, classical conditioning, and hippocampal function. Psychological Review, 99, 268-305.

Schreurs, B. G., \& Kehoe, E. J. (1987). Cross-modal transfer as a function of initial training level in classical conditioning with the rabbit. Animal Learning \& Behavior, 15, 47-54.

Sutherland, N. S., \& Mackintosh, N. J. (1971). Mechanisms of animal discrimination learning. New York: Academic Press.

Sutton, R. S., \& Barto, A. G. (1981). Toward a modern theory of adaptive networks: Expectation and prediction. Psychological Review, 88, $135-170$.

Vogel, E. H., Castro, M. E., \& SaAvedra, M. A. (2004). Quantitative models of Pavlovian conditioning. Brain Research Bulletin, 63, 173-202.

WAgner, A. R., \& Brandon, S. E. (1989). Evolution of a structured connectionist model of Pavlovian conditioning (AESOP). In S. B. Klein \& R. R. Mowrer (Eds.), Contemporary learning theories: Pavlovian conditioning and the status of traditional learning theory (pp. 149-189). Hillsdale, NJ: Erlbaum.

Weidemann, G., \& Kehoe, E. J. (2003). Savings in classical conditioning in the rabbit as a function of extended extinction. Learning \& Behavior, 31, 49-68.

Weidemann, G., \& Kehoe, E. J. (2004). Recovery of the rabbit's conditioned nictitating membrane response without direct reinforcement after extinction. Learning \& Behavior, 32, 409-426.

\section{NOTES}

1. Unlike backpropagation models, the same teacher input is fed to every adaptive unit in both layers. This feature of the model preserves the strength of interior connections during extinction (Kehoe, 1988) and thus prevents catastrophic interference from new learning that characterizes backpropagation models (e.g., Ratcliff, 1990).

2. If all the learning rate parameters were equal, each of the exterior connections could reach the asymptotic value supported by the US. However, in the case of the interior connections (X-R, Y-R, Z-R), the Rescorla-Wagner learning rule would predict that the competition among them would reduce their maximum values to $33 \%$ of the asymptotic value supported by the US. Thus, all the interior connections with the $\mathrm{R}$ unit would have to be activated to reliably generate overt CRs. 


\section{APPENDIX \\ The Basic Model}

The computer simulations of the layered network's functioning was conducted in the following fashion:

(1) The outputs of T1, T2, L, and US sensory units were activated at the 1.0 level when the Tone 1 , Tone 2, Light, and US sensory inputs, respectively, were presented. These outputs were denoted as $O_{\mathrm{T} 1}, O_{\mathrm{T} 2}, O_{1}$, and $O_{\mathrm{US}}$. In addition, there was a moderate overlap in encoding between the two tones, such that when Tone 1 was presented T2 was activated at a 0.2 level; likewise, when Tone 2 was presented, T1 was activated at a 0.2 level. This activation level was based on generalization between comparable tone frequencies seen by Garcia et al. (2003). The activation of the sensory units was bounded from 0 to 1 . The sensory inputs were specified on a trial-by-trial basis and closely approximated the schedules used in the corresponding behavioral experiments.

(2) Each point of connection among the sensory units and the adaptive units had a connection weight designated as $V_{i j}$. The specific connection weights were $V_{\mathrm{T} 1 \mathrm{X}}, V_{\mathrm{T} 2 \mathrm{X}}, V_{\mathrm{LX}}, V_{\mathrm{T} 1 \mathrm{Y}}, V_{\mathrm{T} 2 \mathrm{Y}}, V_{\mathrm{LY}}, V_{\mathrm{T} 1 Z}, V_{\mathrm{T} 2 \mathrm{Z}}, V_{\mathrm{LZ}}, V_{\mathrm{XR}}, V_{\mathrm{YR}}$, and $V_{\mathrm{ZR}}$, where the first term in the subscript refers to the origin of the input, and the second term in the subscript refers to the unit receiving the input. These connection weights started at zero and were unbounded in both the negative and positive directions. The connection weight for the US input to each unit was set at 1.0 to act as a fixed "teacher" input.

(3) The outputs of all units were determined by the product of their input activation and their connection weight. For example, if only the $\mathrm{L}$ input was activated, then the X output $\left(O_{\mathrm{X}}\right)$ would equal $O_{1} * V_{\mathrm{LX}}$. For tone inputs, generalization would be factored in, for example, if the T1 input was activated, then $O_{\mathrm{X}}$ would equal $\left(O_{\mathrm{T} 1} * V_{\mathrm{T} 1 \mathrm{X}}\right)+\left(0.2 * O_{\mathrm{T} 1} * V_{\mathrm{T} 2 \mathrm{X}}\right)$.

(4) Eligible connection weights $\left(V_{i j}\right)$ were changed according to the formula:

$$
\Delta V_{i j}=\alpha_{i j} \beta\left[\lambda-\Sigma\left(O_{i} V_{i j}\right)\right] O_{i},
$$

where $\alpha_{i j}=$ the rate of change parameter for the target unit $(j)$ given the particular input unit $(i) . \beta=$ the rate of change parameter for the US. The US learning rate parameter was higher for acquisition $\left(O_{\mathrm{US}}=1\right)$ than for extinction $\left(O_{\mathrm{US}}=0\right),\left(\beta_{\mathrm{acq}}=.33, \beta_{\mathrm{ext}}=.04\right) . \lambda=$ the total connection weight that could be supported by the US on any given trial ( $\lambda=1.0$ on reinforced trials; $\lambda=0.0$ on unreinforced trials). $\Sigma\left(O_{i} V_{i j}\right)=$ the net sum of the associative strengths of all concurrent eligible inputs to the $j$ th element.

For each trial, the output from the network was computed by first determining the outputs from each of the hidden units $(\mathrm{X}, \mathrm{Y}, \mathrm{Z})$ and then determining the output from the R unit. For example, if the light $\mathrm{CS}\left(O_{\mathrm{L}}=1\right)$ was presented, the outputs from the $\mathrm{X}, \mathrm{Y}$, and $\mathrm{Z}$ units would be $V_{\mathrm{LX}}, V_{\mathrm{LY}}$, and $V_{\mathrm{LZ}}$, respectively. The output from the $\mathrm{R}$ unit would be $V_{\mathrm{LX}} V_{\mathrm{XR}}+V_{\mathrm{LY}} V_{\mathrm{YR}}+V_{\mathrm{LZ}} V_{\mathrm{ZR}}$. Once the outputs had been computed, the formula for changing connection weights would be applied to each activated connection on that trial.

\section{Simulations}

A series of simulations were conducted in which the learning rates $\left(\alpha_{i j}\right)$ were manipulated to determine a set of values that would maximize concurrent recovery while still reproducing savings after extinction — namely, rapid reacquisition and facilitated cross-modal acquisition. At the start of the simulations, all values of $\alpha_{i j}$ were set equal to .20. In preliminary simulations, this value, along with other parameter values as described above, duplicated initial acquisition, extinction, reacquisition, and cross-modal acquisition. However, as will be shown below, this pattern of equal learning rates failed to yield concurrent recovery. In subsequent simulations, the learning rates for the exterior connections were varied so that each sensory unit favored a particular hidden unit (cf. Weidemann \& Kehoe, 2004). Specifically, for the T1-X, T2-Y, and L-Z connections, the learning rate remained at .20, whereas the learning rate for all other exterior connections was reduced to .07 . The learning rates $\left(\alpha_{i j}\right)$ for the interior connections (X-R, Y-R, Z-R) remained at .20.

For each value of the manipulated learning rates, there were simulations corresponding to the major manipulations in the present experiments, namely, initial single-stimulus training (Groups Single and SST), initial T1 versus T2 discrimination training (Groups Discrim and DE), discrimination reversal in Stage 2 (Group DR), and initial tone versus light discrimination training (Group CMD). The simulations were conducted simultaneously to ensure that the model and its parameter values remained consistent at all times. In fact, the simulations revealed that the complete pattern of results could be approximated when the manipulated learning rates were uniformly reduced to .07 . Hence, in all the simulations depicted below, the learning rate $\left(\alpha_{i j}\right)$ for the T1-X, T2-Y, and $\mathrm{L}-\mathrm{Z}$ connections was .20, and the learning rate for the T1-Y, T1-Z, T2-X, T2-Z, L-X, and L-Y was .07.

Initial single-stimulus training. Figure A1 shows the simulation for Groups Single and SST. The top row of panels show changes across blocks of trials in the exterior connections: T1-X (open squares), T1-Y (half squares), T1-Z (solid squares), T2-X (open diamonds), T2-Y (half diamonds), T2-Z (solid diamonds), L-X (open circles), $\mathrm{L}-\mathrm{Y}$ (asterisks), and $\mathrm{L}-\mathrm{Z}$ (solid circles). The middle row of panels shows changes in the interior connections: $\mathrm{X}-\mathrm{R}$ (open squares), Y-R (open diamonds), and Z-R (open circles). Finally, the bottom row shows the simulated percentage CRs on the Tone 1 (open squares), Tone 2 (solid squares), and the light trials (open circles).

During simulated acquisition (the left column of panels) with the single-tone stimulus (T1+), the T1-X, $\mathrm{T} 1-\mathrm{Y}$, and $\mathrm{T} 1-\mathrm{Z}$ connections all developed excitatory values, but the T1-X connection acquired associative 

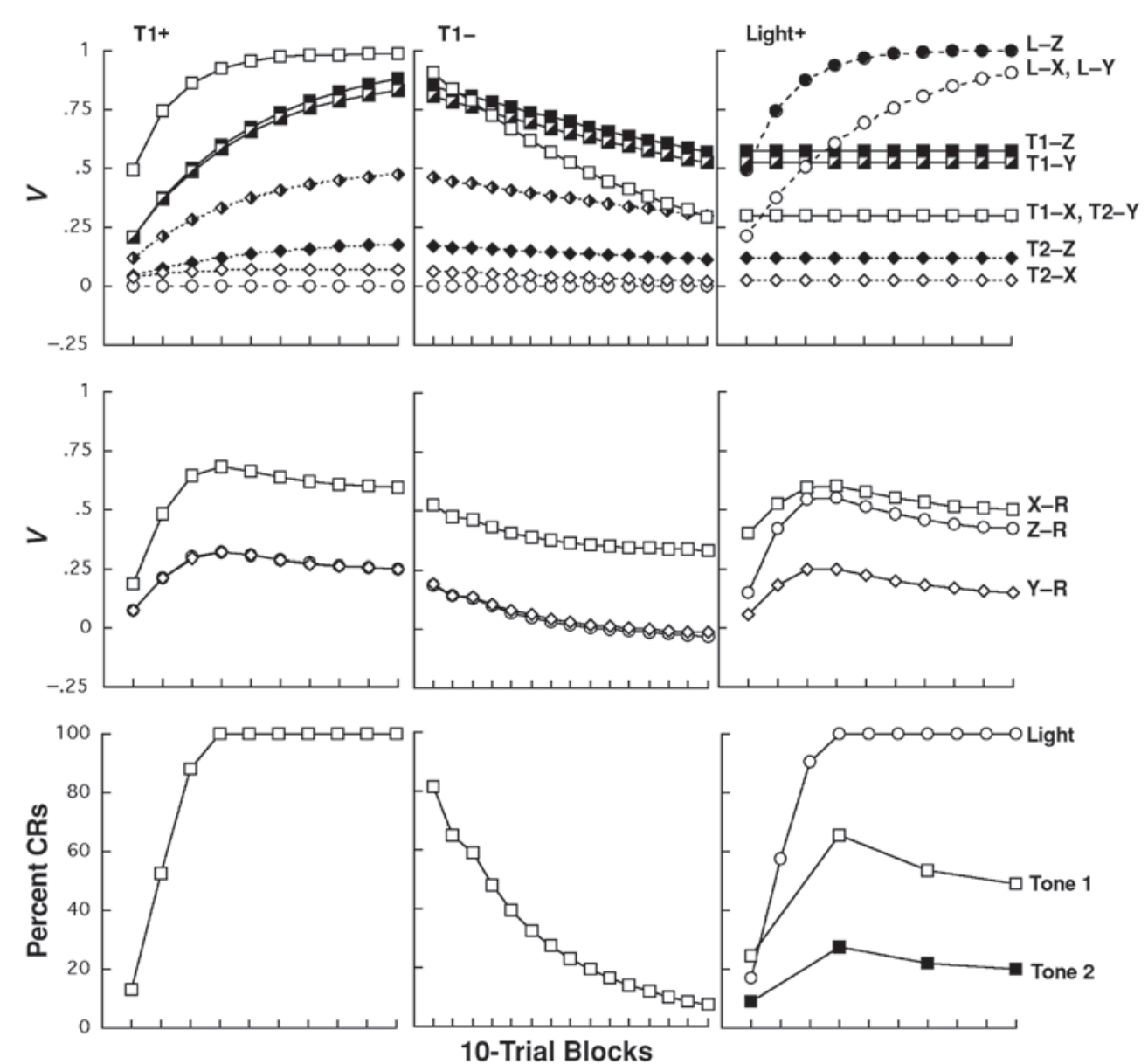

Figure A1. Simulations for all connections and outputs for initial single-stimulus training $(\mathrm{T} 1+)$, extinction (T1-), and final training with a novel stimulus (Light+).

strength faster than either the T1-Y or T1-Z connections. The T2-X, T2-Y, and T2-Z connections also gained some weak excitatory strength as a result of the overlap in stimulus encoding fields of the two-tone stimuli. As a result of the $\mathrm{X}$ unit receiving a stronger input than either the $\mathrm{Y}$ or $\mathrm{Z}$ units, the interior $\mathrm{X}-\mathrm{R}$ connection reached a higher terminal strength than either the $\mathrm{Y}-\mathrm{R}$ or $\mathrm{Z}-\mathrm{R}$ connections.

Subsequent extinction training with the tone stimulus $(\mathrm{T} 1-)$, shown in the center column of panels, resulted in a decrease in the value of all the connections. However, the T1-X connection, with its relatively high learning rate, decreased rapidly. Consequently, the $\mathrm{X}-\mathrm{R}$ connection was protected from further decreases. Conversely, the T1-Y and T1-Z connections changed more slowly and retained much of their strength, thus exposing the $\mathrm{Y}-\mathrm{R}$ and $\mathrm{Z}-\mathrm{R}$ connections to the continued effects of extinction. Thus, the $\mathrm{Y}-\mathrm{R}$ and $\mathrm{Z}-\mathrm{R}$ connections decreased toward zero. The parallel, but weaker exterior connections involving T2 showed a similar pattern of changes. Most importantly, by the end of extinction, only the T1-Y, T1-Z, and X-R connections retained considerable strength, whereas all other connections had been substantially reduced.

As seen in simulations using the predecessor for this network (Kehoe, 1988), the final cross-modal training with the light $(\mathrm{L}+$; right column of panels) reproduced the facilitated acquisition of responding to the orthogonal CS. Specifically, a comparison of acquisition during L + training to initial acquisition during T1 + training reveals that simulated responding to the $\mathrm{L}$ input reached $100 \% \mathrm{CRs}$ in the fourth block of trials, whereas responding during $\mathrm{T} 1+$ training did not reach $100 \%$ CRs until the fifth block of trials. Thus, final cross-modal acquisition required only $80 \%$ as many trials as initial acquisition. Simulation of a naive rest control (not shown) confirmed that acquisition during L+ training would have only reached $100 \% \mathrm{CRs}$ by the fifth block in the absence of any prior training with $\mathrm{T} 1$.

In addition to reproducing facilitated acquisition, the simulations of $\mathrm{L}+$ training yielded concurrent recovery of extinguished responding to T1 and generalized responding to T2. All these effects arose from the ability of the exterior connections to capitalize on interior connections. During the $\mathrm{L}+$ training, the $\mathrm{L}-\mathrm{Z}$ connection increased the most rapidly, but the L-X and L-Y connections also gained strength. As all these connections strengthened, 


\section{APPENDIX (Continued)}

they activated the residual strength of the $\mathrm{X}-\mathrm{R}, \mathrm{Y}-\mathrm{R}$, and $\mathrm{Z}-\mathrm{R}$ connections, thus enhancing the rate of $\mathrm{CR}$ acquisition to $\mathrm{L}+$ training. Concurrently, there was recovery of responding to T1, primarily because the residual $\mathrm{T} 1-\mathrm{Z}$ connection increasingly activated the $\mathrm{Z}-\mathrm{R}$ connection as it gained strength. The T1-Y and $\mathrm{Y}-\mathrm{R}$ connections also contributed to concurrent recovery to T1. Similarly, simulated test presentations of Tone 2 produced some responding, primarily because Tone 2 could partially activate the T1 input and its connections as well as its own weak connections that were established during initial T1 + training.

Initial discrimination training. Figure A2 shows the simulation for Groups Discrim and DE. The figure is organized in exactly the same fashion as Figure A1. A comparison of the two figures reveals that the initial discrimination training (T1+ vs. T2-) made only a small difference in the initial pattern of connection weights. In particular, the simulated T2 - trials caused the T2-X, T2-Y, and T2-Z connections to lose some of their excitatory value across training, but these weights still remained positive. Likewise, during the simulated extinction training, the addition of the T2 - trials to the T1 - trials did not change the key features of the connection pattern obtained in the simulation of Groups Single and SST. Most importantly, at end of extinction the T1-Y, T1-Z, and $\mathrm{X}-\mathrm{R}$ connections still had considerable positive strengths, whereas the T1-X, T2-X, T2-Y, T2-Z, Y-R, and Z-R connections had small residual strengths. This pattern yielded the facilitation of acquisition to the light stimulus, concurrent recovery of responding to $\mathrm{T} 1$, and some generalization of recovered responding to $\mathrm{T} 2$.

The results of the simulation of Group CMD (not shown) exactly matched those of Groups Single and SST. Because the network does not contain any overlap in the sensory encodings of the auditory and visual inputs, the initial cross-modal discrimination training $(\mathrm{T} 1+\mathrm{vs}$. $\mathrm{L}-)$ did not result in any acquisition of associative strength in the exterior connection weights involving the L input, specifically, L-X, L-Y, and L-Z. Consequently, simulations of the subsequent extinction and cross-modal L + training resulted in the same pattern of connections and response output as seen in Groups Single and SST, which conforms to the results seen in Experiments 3A and $3 \mathrm{~B}$.
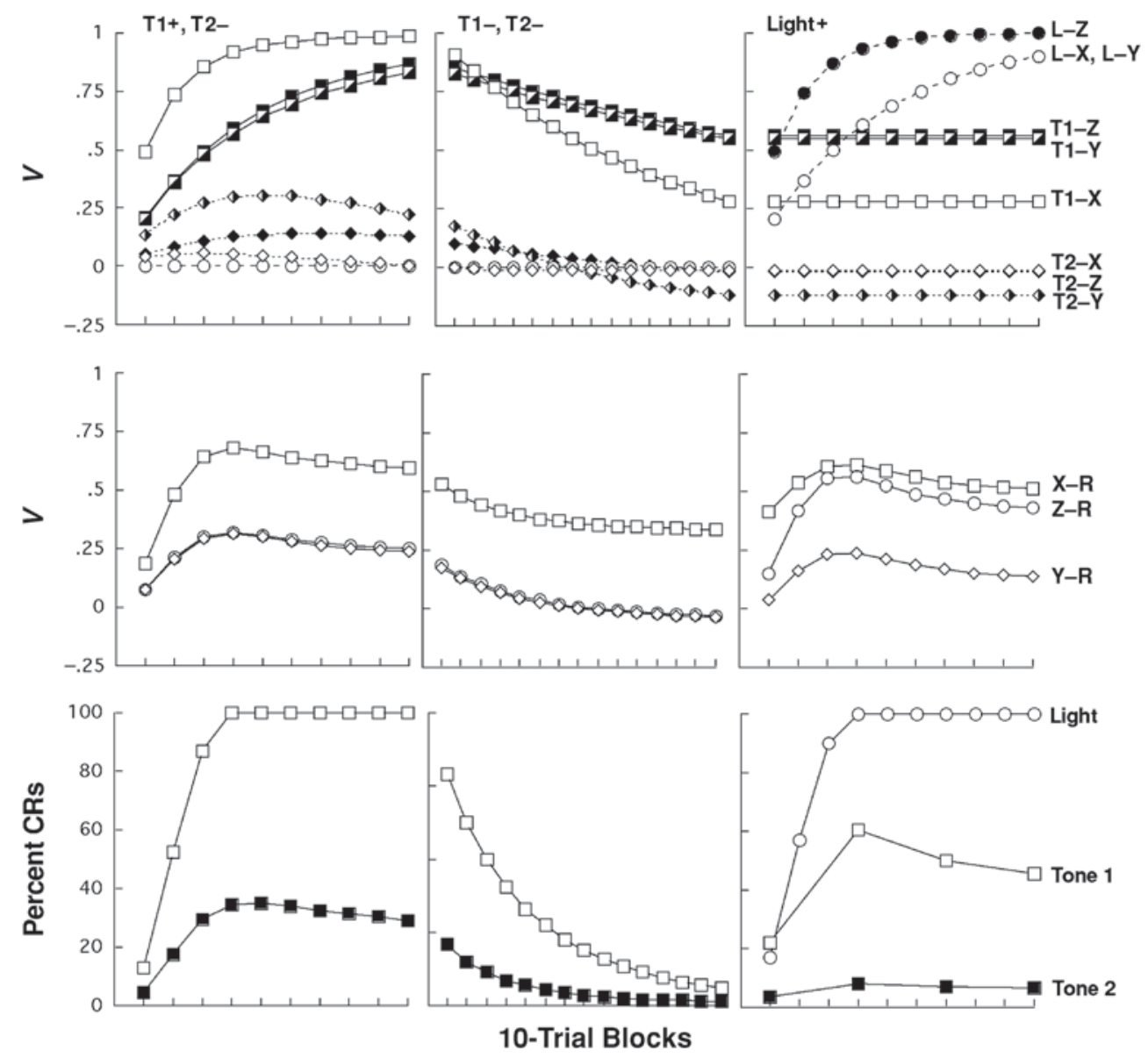

Figure A2. Simulations for all connections and outputs for initial discrimination training (T1+, T2-), extinction (T1-, T2-), and final training with a novel stimulus (Light+). 


\section{APPENDIX (Continued)}

Discrimination reversal training. Figure A3 shows the simulations for Group DR, which received initial discrimination training $(\mathrm{T} 1+\mathrm{vs}$. $\mathrm{T} 2-)$ and then reversal training $(\mathrm{T} 1-\mathrm{vs}$. $\mathrm{T} 2+)$. The key features of the simulations approximated those of Group DR. Specifically, simulated extinction of responding to the T1 during reversal was incomplete in Stage 2 because all intermediate connections of T1 and T2 remained at appreciable levels, as did all the output connections. In Stage 3, simulated responding to T2 remained high and responding to $\mathrm{T} 1$ partially converged with that of $\mathrm{T} 2$.

\section{Conclusion}

The present simulations were guided by the hypothesis that preferential learning rates for each sensory input to a specific hidden unit could explain the emergence of concurrent recovery. Although a more optimal set of parameter settings might be identified, the present simulations were sufficient to provide a proof-of-concept. Specifically, the simulations demonstrated that learning-dependent generalization both within and across modalities can be implemented within a layered network of a type that has previously explained other types of savings seen in the rabbit NM preparation (Kehoe, 1988; Macrae \& Kehoe, 1999; Weidemann \& Kehoe, 2003, 2004).
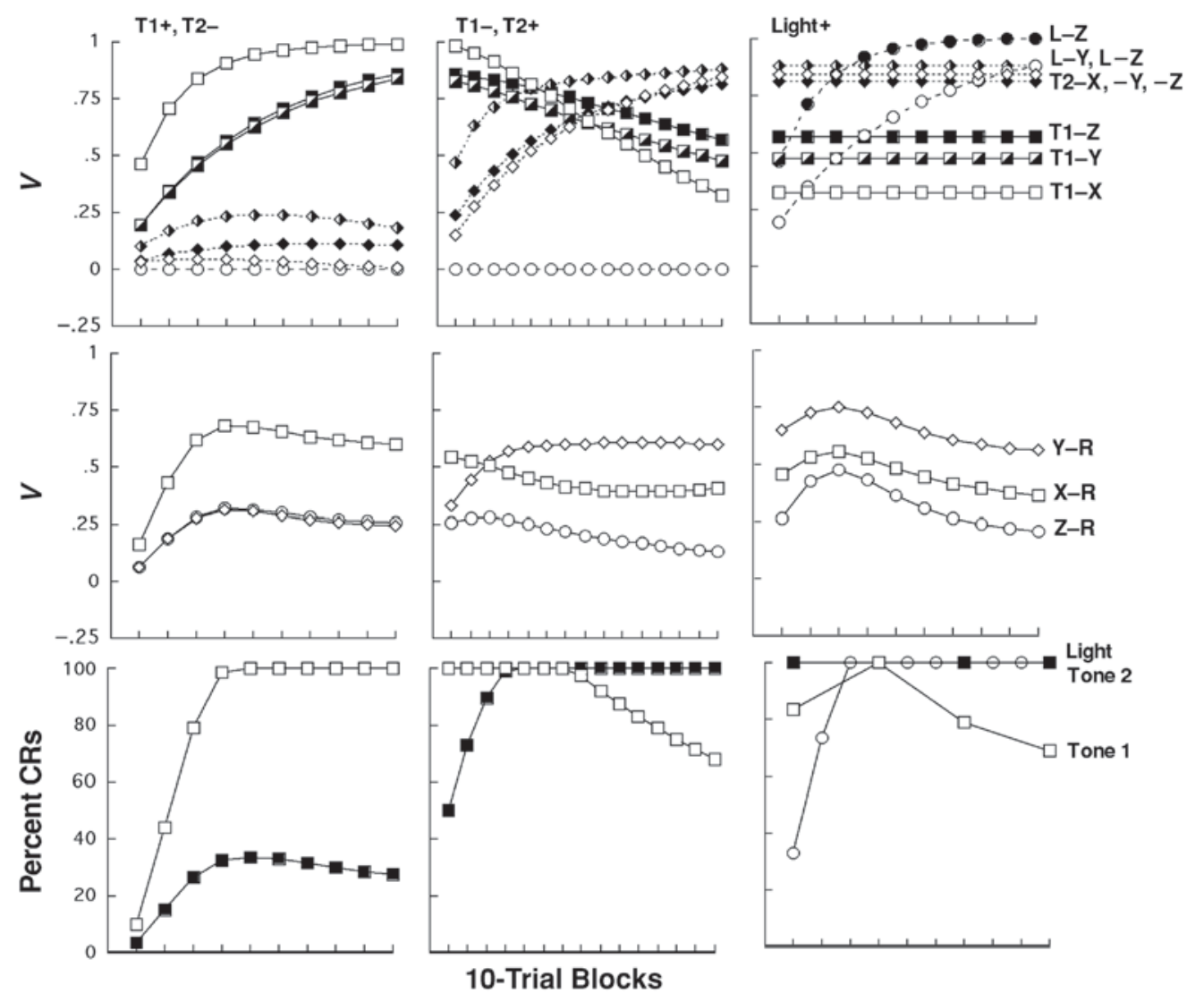

Figure A3. Simulations for all connections and outputs for initial discrimination training $(\mathrm{T} 1+, \mathrm{T} 2-)$, discrimination reversal (T1-, T2+), and final training with a novel stimulus (Light+).

(Manuscript submitted October 31, 2003;

revision accepted for publication September 30, 2004.) 